Est Ag 34 / fasc. 3 (1999) 479-537

\title{
La crucifixión, muerte y sepultura de Jesús según Mc 15, 21-47
}

\section{INTRODUCCIÓN}

El presente trabajo se propone el estudio exegético-teológico de una secuencia de la narración de la Pasión, según el evangelista san Marcos (1415). Esta secuencia $(15,21-47)$ habla sobre la Crucifixión, muerte y sepultura de Jesús. El interés por la investigación sobre este texto ha nacido básicamente de dos motivaciones: la primera, comprender las circunstancias, juntamente con los alcances teológicos, en las cuales Jesús hizo el don de su propia vida en atención a su ministerio de proclamar la Buena Nueva de Dios, comenzando por Galilea hasta llegar a Jerusalén, lugar donde sus más acérrimos adversarios, personificados en los Sumos Sacerdotes, los ancianos y los escribas de la religión judía, le entregaron y le mandaron crucificar por órdenes de Pilato, procurador romano de Judea de aquel entonces.

La segunda motivación, es poner en práctica el nuevo método de la Retórica Bíblica, empleado por R. Meynet ${ }^{1}$, en la interpretación de los textos bíblicos. El cual se interesa por evidenciar, partiendo desde un punto de vista sincrónico, la construcción simétrica de los escritos, sea veterotestamentarios como neotestamentarios. Este método se diferencia de la Crítica Retórica o la llamada Retórica Clásica, en la medida en que ésta parte de los

1. Para la consulta acerca de este nuevo método pueden verse principalmente dos obras del mencionado autor: L'analisi retorica, 142-262; E ora, scrivete per voi questo cantico. Introduzione prattica all'analisi retorica, 25-113; igualmente puede consultarse un artículo suyo: "Un nuovo metodo per comprendere la Bibbia: l'analisi retorica", 403-436; una presentación de este método figura también en el Documento de la Pontificia Comisión Bíblica: La interpretación de la Biblia en la Iglesia, 36-39. 
presupuestos de la retórica grecolatina; en cambio el análisis retórico, como también se le llama, tiene en cuenta la tradición literaria bíblica, con su uso característico del paralelismo de términos.

El uso del método comporta la utilización de las leyes que contiene la retórica hebrea en la escritura de tipo poético y en la de tipo prosaico. El asunto, en primer lugar, es identificar y delimitar las unidades literarias mínimas, tales como los términos, es decir, un lexema o monema lexical, como "cruz", "pasar", "hora", "oscuridad", "grande"; los segmentos, que pueden ser unimembre, bimembre o trimembre; un miembro está compuesto por uno, dos o tres términos. Se reconoce un miembro de un segmento cuando un conjunto de términos construyen un enunciado con un significado, valor o sentido determinado; los fragmentos se componen de uno, dos o tres segmentos. En segundo lugar, se debe demarcar las unidades literarias mayores, como los pasajes, compuestos de uno o más fragmentos; las subsecuencias, compuestos uno o más pasajes; las secuencias, formadas por una o más subsecuencias; las secciones, constituidas por una o más secuencias; hasta llegar al análisis de un libro que está compuesto por una o más secciones.

Así, el acercamiento que se pretende en el texto marciano elegido, comporta previamente la crítica textual de los versículos que presentan problemas en este nivel, seguido de los problemas gramaticales y lexicográficos más relevantes que aparecen en estos versículos, con la finalidad de contextualizarla conforme al mundo bíblico, en el griego clásico y de acuerdo al estilo narrativo del autor. Después podrá encontrarse al inicio de cada pasaje una versión de la traducción del texto griego que es el resultado de la labor anterior, y servirá para la subsiguiente profundización en la línea interpretativa. Este presupuesto es de singular importancia dado que cuanto más literal o respetuosa del texto original sea la traducción, cuando es posible, ayuda a reconocer la función retórica de los términos que el autor mismo les ha asignado en el momento de poner por escrito su obra. Antes de la interpretación propiamente dicha, se hará el análisis de la secuencia que se divide en tres subsecuencias ( vv. 21-32;33-36 y 37-47); la primera y la tercera compuesta cada una de dos pasajes, y la segunda de un solo pasaje. Finalmente, se propondrán unas conclusiones.

Uno de los límites de este estudio, entre otros, que podrá encontrar el lector, es que no abarca la totalidad de la obra del así llamado evangelista Marcos, que permitiría captar con mayor claridad el lugar que ocupa esta secuencia en el conjunto del libro. Por ejemplo, los títulos cristológicos que comparecen en este texto, son como la conclusión de lo que se ha venido señalando a lo largo de este Evangelio, empezando ya desde el primer versículo, donde Jesús es llamado Hijo de Dios, título éste que viene puesto en 
boca del centurión confesando su fe: "verdaderamente este hombre era Hijo de Dios. Igualmente el Reino de Dios”, que José de Arimatea estaba esperando, es ya parte de esta obra en 1,15 que Jesús empezó a proclamar con estas palabras: "El tiempo se ha cumplido y el Reino de Dios está cerca; convertíos y creed en la Buena Nueva". Con estos ejemplos se puede caer en la cuenta de cómo las cosas que van narrándose evocan cosas ya dichas, ayudando a una comprensión más global no solamente de los títulos cristológicos, sino también de cada uno de los versículos que van a ser estudiados, tratando de encontrar el mensaje.que encierran. Este aspecto, además, es fundamental en la retórica bíblica en la medida en que los términos, que se evocan unos a otros, forman un conjunto compacto y bien estructurado.

Por otro lado, hay cosas que son dichas en este texto de las que el autor no da ulteriores explicaciones, y que cuando se confrontan con el resto de los sinópticos difieren, si no totalmente, al menos en parte. Está, por ejemplo, la bebida ofrecida a Jesús en el último momento de su vida. Según Marcos: Alguien, corriendo, y empapando una esponja en vinagre, sujetándola a una caña, le ofrecía de beber diciendo: "Dejad, veamos si viene Elías a descolgarle" $(15,36)$, mientras en Mateo (27,48-49), son los otros los que pronuncian la frase con el mismo tenor. Del mismo modo queda inexplicada la confusión del grito de Jesús que invoca a Dios, con una supuesta invocación al profeta Elías. La presencia de Simón de Cirene, la de José de Arimatea, del centurión, de las mujeres, que irrumpen en la narración sin anticipación alguna. Ante lo cual, para lograr una interpretación no armonizante de los evangelios, hay que buscar una explicación más o menos cercana a lo que el autor quiso decir con esta particular narración. De modo tal, esta propuesta se propone explicar estos y otros problemas que aparecen en este texto tal y como se presentan hoy en día.

En lo que sigue se desarrollarán los puntos que se han señalado. No sin antes agradecer encarecidamente al Profesor R. Meynet que ha acompañado este trabajo con sus oportunas observaciones. 


\section{TEXTO}

\subsection{CRÍTICA TEXTUAL}

Después de una lectura del aparato crítico, es de destacar que no todas las variantes que aparecen merecen una especial atención, de modo que se debe hacer una selección, fijándose sobre todo en aquellas que afectarían al conjunto y al sentido del texto (15,21-47). Hay que advertir que para esta selección hay estudios precedentes que sirven como punto de apoyo, cada uno con una u otra visión, unas veces coincidiendo entre sí, otras discrepando, como se verá en esta parte del trabajo.

- v. 25 Considerando la delimitación del tiempo que Marcos hace en la sección de la Pasión de Jesús (14-15), de días, de horas, de amanecer, de atardecer, de noche, merece atención en primer lugar el v. 25. Este versículo ofre-

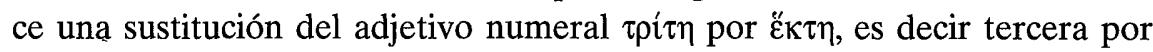
sexta hora, avalado por los testimonios $\Theta p c$ Symg $^{\text {hm }}$. Por un lado, desde un punto de vista interno, en el texto 15,21-47, hay una puntual demarcación del tiempo, incluido este versículo. Las subsiguientes alusiones cronológicas son la hora sexta (v. 33a), la hora nona (v. 33b.34) y el día, que se cierra con una indicación de la llegada de la tarde, que a su vez va relacionado con la observación del amanecer de 15,1, la aclaración de que ha pasado el sábado y es el primer día de la semana de 16,1-2. Además con la exacta numeración sucesiva de tercia, sexta y nona, períodos divididos cada uno en tres horas.

Por otro lado, el problema surge cuando este dato de la hora en Marcos es confrontado con el evangelio de Juan que para el mismo evento habla de la hora sexta $(19,14)$, un dato que en los otros dos restantes sinópticos no aparece ${ }^{3}$. Según V. Taylor, se han dado diversas explicaciones, pero "ninguna de ellas es convincente" "4, por ejemplo que Juan sigue el cálculo romano de las horas, que la $F$ (digamma que equivalía al seis) ha sido confundido con la $\Gamma$ (gamma mayúscula que equivalía al tres) por los transcriptores o que los judíos crucificaron realmente a Jesús cuando gritaron: "crucifícalo". Por lo mismo, es mejor reconocer en las indicaciones temporales dos tradiciones diferentes. En este sentido se entiende que Juan es una corrección y que la lectura de

2. $\Theta$ (Codex Coridethianus, s. IX), $p c$ (unos pocos manuscritos), sy hmg (variante siríaca en el margen de la Harclense).

3. cf. K. Aland, Synopsis Quatuor Evangeliorum, 483.

4. V. TAYLOR, The Gospel According to St. Mark, 590.

5. cf. V. TAYLOR, op. cit., 591. 


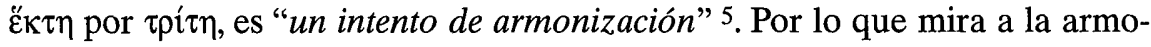
nización B.M. Metzger ${ }^{6}$ es de la misma opinión que V. Taylor.

Si aceptamos la variante de $\Theta p c$ Sy ${ }^{\text {hmg }}$, romperíamos con la organización cronológica del conjunto de la narración. De modo que la lectura propuesta en la edición $27 \mathrm{ma}$. del Nestle- Aland ${ }^{7}$ resulta la más admisible.

- v. 28 Hay testimonios que insertan el entero v. 28: $\kappa \alpha \iota \varepsilon \pi \lambda \eta \rho \omega \theta \eta \eta \gamma \rho \alpha \phi \eta$ $\eta \lambda \varepsilon \gamma o v \sigma \alpha \kappa \alpha \imath \mu \varepsilon \tau \alpha \alpha \nu \circ \mu \omega \nu \varepsilon \lambda \sigma \gamma \imath \sigma \tau \eta=y$ se cumplió la Escritura que dice: con los malvados fue contado, L $\Theta 0830250 f^{1.13} 33 \mathfrak{M R}_{\text {lat sy }}{ }^{\text {ph }}$ (bo ${ }^{\mathrm{pt}}$ ) Eus. Mas, la omisión en los mejores y más antiguos manuscritos $\aleph$ A C D $\Psi 2427 p c \mathrm{k}$ Sy ${ }^{\mathrm{s}}$ sa bo ${ }^{\mathrm{pt}} \mathrm{y}$ la forma de citar del A.T., que en Marcos es muy rara, hacen pensar que la inserción del v. 28 sea más bien una asimilación de Lc 22, 37, que a su vez trae reminiscencias del cuarto canto del Siervo Sufriente de Is 53, 128 . Este versículo no pertenecería al texto original marciano. Probablemente sea un añadido posterior realizado por los copistas bajo la influencia de Lc 22,37; así, hay dos opciones: se omite el versículo, o se considera parte del capítulo. Si se opta por la segunda posibilidad, las razones para explicar la influencia lucana para su inserción no son convincentes, dado que el contexto de Lc 22,37 es totalmente distinto al de Marcos; en Lc la alusión a Is 53,12 está en los preliminares de la crucifixión, en cambio en Mc esta alusión se situaría en el momento mismo de la crucifixión. A su vez, cuando Lc narra la crucifixión no hace ni la menor alusión al cuarto canto del Siervo (cf. Lc 23,33-34). La primera posibilidad está más de acuerdo con el estilo sintético de Marcos. Es difícil optar una de las alternativas. En este trabajo se considerará el versículo en cuestión como parte del conjunto narrativo.

- v. 34 Se presenta una doble dificultad: primero, en la lectura del grito de Jesús: E $\lambda \omega \imath \varepsilon \lambda \omega \imath \lambda \varepsilon \mu \alpha \sigma \alpha \beta \alpha \chi \theta \alpha v \imath$, el paralelo de Mt 27, 46b lee $\eta \lambda \imath \eta \lambda \imath$ conjuntamente con $\mathrm{D} \Theta 059565 p c$ it vg ${ }^{\mathrm{mss}}$ Eus. Igualmente la frase $\lambda \varepsilon \mu \alpha \sigma \alpha \beta \alpha \chi-$ $\theta \alpha v t$ ha tenido varias lecturas y escrituras, comenzando con la anterior edición del Nestle-Aland ${ }^{25}$ leía $\lambda \alpha \mu \alpha \sigma \alpha \beta \alpha \chi \theta \alpha v$ unido a B (con una ligera variante: $\zeta \alpha \beta \alpha \phi \theta$.) $\Theta 059$ etc., otros leen $\lambda \iota \mu \alpha \sigma \alpha \beta \alpha \chi \theta \alpha \nu \imath \mu$ con una ligera variante de A: $\sigma \alpha \beta \alpha \kappa \tau-f^{13} 33 \mathrm{M}$ sy ${ }^{\mathrm{h}}$, también $\lambda \alpha \mu \alpha \zeta \alpha \phi \theta \alpha \vee \mathrm{D}$ (i) vg ${ }^{\mathrm{mss}}$. El texto que se propone en esta edición está fundado en $\aleph \mathrm{CL} \Delta \Psi$ etc.

Las variantes muestran que los testimonios son dispares y, por tanto, nuestro texto es complicado y polémico. V. Taylor afirma que es "la transliteración

5. cf. V. TAYLOR, op. cit., 591.

6. cf. B.M. METZGER, A textual commentary on the Greck New Testament, 99.

7. cf. Nestle-Aland, Novum Testamentum Graece, 144.

8. cf. V.TAYLOR , op. cit, . 591; también B.M. METZGER, op. cit., 99; W.L. LANE, The Gospel of Mark, 651; R. Pesch, "Il Vangelo di Marco, Parte Seconda, Texto Greco e Traduzione, Commento ai Capp. 8, 27- 16, 20", 706. 
hebraizada de un original arameo del Sal 22,1" (sic; se trata en realidad del v. 2), donde si Marcos usó una tradición palestina es natural que refiera el dicho en forma aramea; pero es más probable que el dicho de Jesús haya sido lanza-

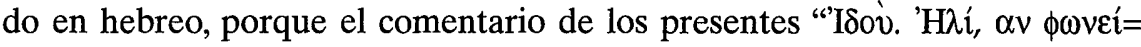
Mira, a Elías llama" $(15,35)$, es inteligible si Jesús gritó $\eta \lambda \varepsilon \imath ~ \eta \lambda \varepsilon \imath$ o $\eta \lambda \imath ~ \eta \lambda \imath$ en vez que $\varepsilon \lambda \omega t$. En Mt 27,46 solamente $\aleph$ B $33 \mathrm{vg}(m u)$ sa bo aeth leen lo último; otros testimonios tienen uno de los dos $\eta \lambda \varepsilon \imath$ o $\eta \lambda \iota$, formas que fácilmente pueden ser confundidas con אליזיה o Elías. El mismo V. Taylor hace un elenco de los estudiosos que defienden la posición de que Jesús ha utilizado la forma hebrea y de los estudiosos que respaldan la forma aramea, para finalmente decir que mucho depende del carácter histórico de los vv. 35-36b 9 .

Por otra parte, B.M. Metzger aclara que los testimonios que leen $\eta \lambda \varepsilon$ $\eta \lambda \varepsilon 1$ o las variantes $\varepsilon \lambda \varepsilon 1$ o $\eta \lambda \imath$ representa el hebreo ("Dios mío"), que luego ha sido asimilado por el paralelo de Mt $(27,46)$. Igualmente, este autor opina que la gran mayoría de los manuscritos unciales y de los minúsculos han leído $\varepsilon \lambda$ $2 \lambda 01$ que representa al arameo ("Dios mío") el cambio de la $\omega$ por la $\alpha$ es "debido a la influencia del hebreo

W.L. Lane cree en la probabilidad de que los códices que tienen una lectura similar a la de Mt 27,46 han conservado la forma original de la frase, conforme al Targum del Sal 22,2 que tiene en hebreo eloi eloi y la pregunta en arameo (¿lama sabachthani?) ${ }^{11}$.

Si bien la lectura de Mt 27,46 y los testimonios que lo acompañan leen $\eta \lambda \iota \eta \lambda \iota$ conforme a la versión actual de la Biblia Hebraica Stuttgartensia, hay que admitir que la versión marciana, tal como es presentada ahora en el Novum Testamentun Graece ${ }^{27}$, representa al original arameo hebraizado.

Todos los manuscritos griegos excepto el Codex Bezae leen $\sigma \alpha \beta \alpha \chi \theta \alpha v \imath$ o algo similar ( $\sigma \curlywedge \beta \alpha \kappa \theta \alpha v \varepsilon \imath, \mathrm{A} ; \zeta \alpha \beta \alpha \phi \theta \alpha v \varepsilon \mathrm{l}, \mathrm{B} ; \sigma \alpha \beta \alpha \chi \theta \alpha v \varepsilon \mathrm{l}, \mathrm{C}$ al), que representa

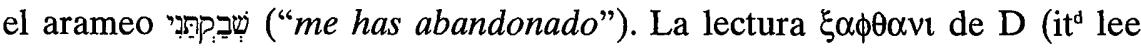

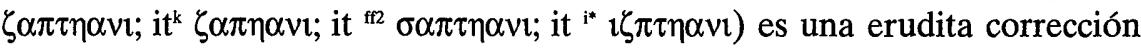

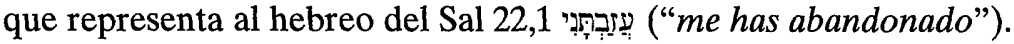

Así, "en el texto elegido por el Comité la frase entera representa un arameo original, mientras el paralelo de Mateo es en parte hebreo y en parte arameo" 12.

8. cf. V.TAYLOR , op. cit, . 591; también B.M. METZGER, op. cit., 99; W.L. LANE, The Gospel of Mark, 651; R. PESCH, "Il Vangelo di Marco, Parte Seconda, Texto Greco e Traduzione, Commento ai Capp. 8, 27- 16, 20", 706.

9. cf. V. TAYLOR, op. cit., 593.

10. cf. B.M. METZGER, op. cit. 99-100.

11. cf. W.L. LANE, op. cit., nota 65,570 .

12. cf. B.M. METZGER, op. cit., 100. 
La dificultad que presenta la lectura del texto que sigue es evidente, puesto que, la traducción al griego omite el primer $\mu$ ov como lo testimonian A K P $\Gamma \Delta \Theta 059$ etc., a continuación también se omite enteramente el segun-

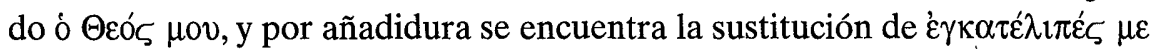
por $\omega v \varepsilon 1 \delta เ \sigma \alpha \zeta \mu \varepsilon=$ me has rechazado. Esto último supone una postura teológica, en el sentido de que la oscuridad debe ser interpretada como una sanción de maldición sobre Jesús; mejor, alguien que no podía comprender cómo Dios habría abandonado a Jesús en la cruz ${ }^{13}$. De cualquier manera también el texto presentado en esta edición tiene códices de primer orden para Marcos que respaldan esta segunda parte del v. 34 \ B $\Psi 059$ etc.

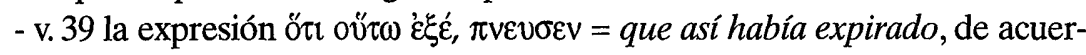
do a diversos testimonios ha sido leída de cuatro maneras diferentes: a) cuando el Centurión vio "que así había expirado"( B L $\Psi$ 892, etc.); b) "que habiendo

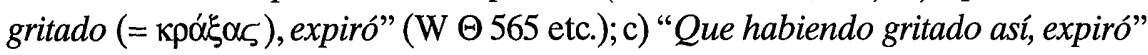
(A C K $\Theta f f^{1.13}$ etc.); d) "que así gritando, expiró" (y omite $\left.\varepsilon 1 \pi \varepsilon v=d i j o\right)(\mathrm{D})$. Aparentemente la primera lectura representa la forma más antigua del texto ${ }^{14}$, debido a que por un lado, es la lectura más breve como corresponde al estilo sintético de Marcos; por otro lado, la lectura más larga parece ser debida a la influen-

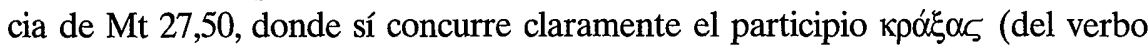

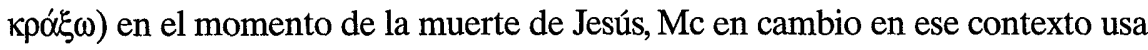

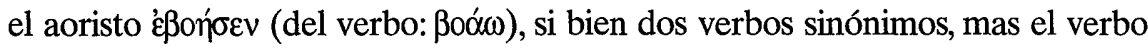
ßoóc $\omega$ aparece solamente dos veces en Mc, cuando se habla de Juan el Bautista (cf. Mc 1,3; el par. de Mt 3,3 usa el mismo verbo y es la única vez que lo hace) y para referirse al fuerte grito de Jesús en la cruz (cf. Mc 15,34). Diversamente, para expresar el grito de otros personajes Mc usa el verbo кpó́k $\omega^{15}$.

\subsection{LEXICOGRAFÍA}

Las voces que se presentan a continuación son algunos términos que confirman el uso que se hacía de los mismos en el mundo griego (cfr. la versión de los LXX), o eran traducción provenientes de la lengua hebrea o aramea:

13. cf. W.L. LANE, op. cit., nota 66, 570; también: B.M. METZGER, op. cit., 100.

14. cf. W.L. LANE, op. cit., nota 68,571 .

15. cf. Mc 3, 11; 5, 5.7; 9, 24.26; 10, 47.48; 11,9;15, 13.14. Por lo demás, es interesante consta-

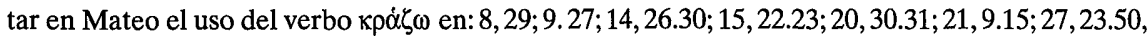
en siete ocasiones es usado para referir una confesión de la persona de Jesús como el "hijo de David", una como "hijo de Dios" $(8,29)$, los discípulos para decir que es "un fantasma", una en boca de Pedro "Señor, Sálvame", una en boca de los judíos "sea crucificado" y para reportar por única vez el grito de Jesús (El hijo de David, el hijo de Dios), pero sin pronunciar palabra alguna, se hace constar solamente el grito.

16. cf. L. RocCI, "’’ $\gamma \gamma \alpha \rho \varepsilon v ́ o v \sigma t v-\varepsilon v ́ \omega ", V G I, 7$.

17. cf. W. ARNDT - F.W. GINGRICH, " $\alpha \gamma \gamma \alpha \rho \varepsilon v ́ \omega ”, ~ G E L N T, 766$. 


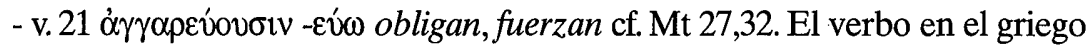
clásico significa: expedir un correo ${ }^{16}$. Su origen no es netamente griego, sino proviene de la lengua persa, donde el $\alpha$ $\gamma \gamma \alpha \rho \rho_{\zeta}$ era un medio, un servicio de correo a caballo o en barco de la casa real ${ }^{17}$, y el encargado del servicio postal, tenía la facultad de exigir los medios (sea personas, animales, o alimento), para llevar a término esta tarea; de aquí pasó a significar cualquier acto de requisición ${ }^{18}$, es decir, "el recuento y el embargo o expropiación de ciertos bienes de propiedad particular considerados aptos para las necesidades de interés público" 19.

Los condenados a la crucifixión ${ }^{20}$ debían ser desnudados y cargar el travesaño ("patibulum") de la cruz desde "el pretorio o de la cárcel, hasta el lugar de la ejecución, mientras los soldados seguían flagelándolos" 21 . A Jesús no le desnudaron, ni siguieron flagelándole durante el camino al lugar del suplicio, porque antes de sacarle fuera le pusieron sus ropas (cf. Mc 15,16-20), y seguramente cargó con el "patibulum" una cierta distancia, hasta que los soldados se dieron cuenta que Jesús ya no podía más. Entonces los soldados hicieron el uso del derecho de angaria 22 o requisición. Este último sentido es el que denota el verbo cuando Marcos lo usa en 15,21, que es el de "obligar a uno a que preste un servicio, un trabajo", como en Mt 5,41;27,32. Al mismo tiempo, está el hecho de que en Marcos este verbo es un hapax legómenon 23.

Según S. Légasse, en el hecho de la requisición de Simón, no se puede excluir de la mente del redactor un recuerdo de la advertencia pronunciada

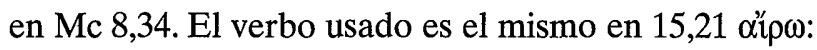

«El hombre requerido para "tomar" (hina arêi) la cruz de Jesús evoca a aquellos a los que Jesús se dirigía al decir: "Si alguien quiere seguirme, que renuncie a sí mismo y que tome (aratô) su cruz y me siga"» 24 .

18. cf. F.M. URICCHIO - G.M. STANo, Vangelo secondo Marco, 628.

19. cf. Diccionario de LA Lengua EsPañola, Tomo II, 1778.

20. El suplicio de la cruz pasó de los persas a los cartagineses, y de estos a los romanos; quienes lo aplicaron largamente contra los esclavos, los sediciosos, los delincuentes más peligrosos y especialmente para prevenir y reprimir las rebeliones de los pueblos subyugados. Prohibida para los ciudadanos romanos, esta pena infamante y cruel era considerada como un suplicio para los esclavos. En el Antiguo Testamento no se conocía el castigo de la crucifixión, se usaba la lapidación como condena a muerte (Dt 21,21-23) y como aumento de la ignominia para con los ajusticiados se colgaban sus cadáveres (Gn 40,19; 1 S 31, 10; 2 S 4, 12), cf. F.M. URICCHIO- G.M. STANO, op. cit., 627; también: J. RADERMAKERS, Lettura pastorale del vangelo di Marco, 314; H. HAAG- A. van den BORN- S. de AUSEJO, "Crucifixión", DB, 404-405.

21. cf. F.M. URICCHIO-G.M. STANO, op. cit., 628.

22. cf. P. BillerbeCK, - H. STRACK, Kommentar zum Neuen Testament aus Talmud und Midrasch, Vol I, 344; también: PESCH, R., L'evangelo della comunità primitiva, 200; Id., art. cit, 698.

23. cf. M. GUERRA GÓMEZ, op. cit., 151.

24. S. LÉGASSE, El proceso de Jesús. La Pasión en los cuatro Evangelios, 92. 
Ciertamente se puede objetar, como afirma el mismo S. Légasse, que la cruz que lleva el Cireneo no es la suya sino la de Jesús. En Mc 8,34 las palabras tòv $\sigma \tau \alpha$ vò̀ $\alpha$ v่ $\tau 0 \hat{v}$, designan la cruz de aquel que sigue a Jesús; en Mc 15,21 designan la cruz de Jesús. Por otra parte, su colaboración no tiene nada de voluntaria, y en consecuencia cuadra mal con 8,34. Sin embargo, como Marcos y con él Mateo 27,32 no menciona explícitamente esta evocación de 8,34 , lo que sí parece haberlo hecho Lucas 23,26 quien menciona que Simón iba "detrás de Jesús" 25. Esto no quita que se pueda intuir esta posibilidad como parte del deseo y del propósito de Marcos, toda vez que encuadra bien con el tema del discipulado que entra dentro del marco comprensivo de la totalidad del evangelio Marciano.

Por otro lado, está el hecho de que el uso que hace Marcos del verbo $\alpha \gamma-$ $\gamma \alpha \rho \varepsilon v ́ \omega$ en el contexto del llevar la cruz, puede indicar muy bien que la intención de Marcos sea la de "mostrar que Simón presta el servicio al nuevo rey" 26.

- àrpós sin artículo, campo (en oposición a ciudad). Aquí probablemente Marcos haga referencia como en 6,36 a las alquerías, las casas de labranza o una granja lejos del poblado. En 6,56, lo mismo que en la citación precedente, Marcos se refiere a estas casas que están fuera de la ciudad. Se hace sucesivamente la diferencia entre aldeas y alquerías (campos) ${ }^{27}$, más claramente en el v. 56 aldeas, ciudades, alquerías, plazas. Esta misma connotación se repite en 16,12 donde se habla de dos de sus discípulos que iban a la alquería. En cada uno de los casos la palabra griega es la misma.

Esto puede ayudar a comprender a qué hacía referencia Marcos cuando menciona que Simón "volvía del campo". No necesariamente quiere decir que volvía de trabajar. Como dice V. Taylor, podía ser que, como judío que era, regresaba de uno de estos lugares del campo a la ciudad de Jerusalén para celebrar la Pascua. Es impreciso decir que esta alquería de donde regresaba era suya, que habría heredado de sus padres ${ }^{28}$. Lo mismo este hecho no prueba que Simón fuera un campesino que volvía de trabajar ${ }^{29}$. Ambas afirmaciones son solamente especulaciones siempre que el texto no informa nada al respecto. Se excluye también el hecho de que Simón fuera un pagano, contra

25. Ibid., 92.367-368. Lucas evita hablar aquí de requisición, como lo hacen Marcos y Mateo, lo que hace es remplazar el verbo de origen persa aggareuein por un verbo ciertamente griego, epilambanesthai («echar mano de [...]»).

26. cf. R. MEYNET, Passion de notre Seigneur Jésus Christ, 169.

27. cf. Diccionario de la Lengua Española, Tomo I, 113; F. Lacueva, Nuevo Testamento interlineal Griego-Español, 164.166.212.216.

28. cf. M. GALIZZI, Vangelo secondo Marco, 291.

29. cf. V. TAYLOR, op. cit., 588.

30. cf. J. Mateos, - F. CAMACHo, Marco, 379. 
J. Mateos-F. Camacho ${ }^{30}$ quienes dicen que sería uno de los muchos que seguían a Jesús $(2,15 ; 3,32.34 ; 5,24)$ y estaban en torno al Maestro, ya que en Cirene vivían los judíos de la diáspora (Hch 2,$10 ; 11,20 ; 13,1)$. Lo probable es que este hecho inesperado en su vida haya sido el inicio de su conversión ${ }^{31}$, aunque de esto Marcos tampoco hace una ulterior precisión.

Otra dificultad ligada al hecho de que Simón volvía del campo, es la cuestión de la cronología, es decir: ¿qué día fue ejecutado Jesús? ${ }^{32}$. Si antes de la fiesta de Pascua, de acuerdo con la cronología de Juan (Jn 18,28; 19,31), el 14 del mes de Nisán, o como señalan los sinópticos, el 15 del mes de Nisán (cf. Mc 14,12.16; Mt 26,17-19; Lc 22,7-15), el día de la Pascua. En lo que sí están de acuerdo es que ese día era viernes, la víspera del sábado (cf. Mc 15,42; Mt 27,62; Lc 23,54.56; Jn 19,31.42). Si era el día de Pascua, entonces Simón de Cirene que "volvía del campo" insinuaría una infracción de parte suya al reposo prescrito el día de Pascua. Como ya se señaló arriba el texto no dice que "volvía de trabajar" en el campo, por tanto no se puede confirmar tal infracción. La cuestión de la cronología, como se indicó en la crítica textual, responde a cuestiones de tipo teológico más que a razones estrictamente históricas.

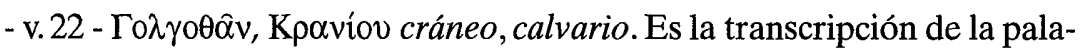

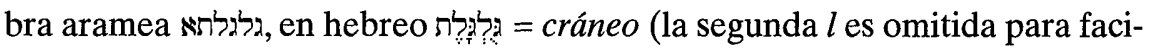
litar la pronunciación griega; este nombre le fue dado por el pueblo, probablemente por la forma característica de la roca, "emergente como una cabeza pelada" 33. X. Pikaza, dice que el lugar del cráneo, está relacionado con la muerte ${ }^{34}$. De hecho las 12 veces que aparece en el Texto Masorético, en tres de esas viene usado en un contexto de muerte (cf. Jc 9,53; 2 R 9,35; 1 Cro 10,10 , las otras veces se usa para significar «cabeza, uno por uno o cabeza por cabeza» (cf. Ex 16,16; 38,26; Nm 1,2.18.20.22; 3, 47; 1 Cro 23,3.24). M. Völkel 35 , añade los sinónimos de calavera y cabeza; y que probablemente el lugar de la crucifixión haya sido simplemente una colina, teniendo en cuenta que en árabe, para designar una colina, se usa el término rãs = cabeza. No existe certeza alguna dónde estaba situado ese lugar, lo único que señalan los evangelios es que quedaba extramuros de la ciudad de Jerusalén (cf. Mc 15,22; Mt 27,$33 ;$ Jn 19,17.20).

31. cf. X. PIKAZA, Il vangelo di Marco, 407-408.

32. cf. S. LÉGASSE, El proceso de Jesús. La historia, 113-118; J. GNILKA, op. cit., 742-744.759764

33. cf. K.W. CLARK, "Golgotha", IDB, 439; G. NolLI, Evangelo secondo Marco; texto greco, neovolgata latina analisi filologica, traduzione italiana, 405.

34. cf. X. PIKAZA, op. cit., 408.

35. cf. M. VÖLKEL, "Гoג $\gamma 0 \theta \hat{\alpha}, \hat{\alpha} v ", D E N T, 775-777$. 
- v. $23 \sigma \mu \nu \rho v^{\prime} \zeta \omega, \sigma \mu v ́ p v \alpha$ la sustancia resinosa de la mirra es producida por árbol homónimo perteneciente a la familia de las burseráceas, característica sobre todo de Arabia meridional y de Abisinia septentrional, es amarga, produce un perfume intenso. En el AT aparece en Ex 30, 23; Sal 45 (44), 9; Si 24,$15 ; \mathrm{Ct} 3,6 ; 4,14 ; 5,5.13 ;$ Est 2,12 (ר= mirra). El verbo $\sigma \mu \nu \rho \operatorname{i} \zeta \omega$, que fuera de la Biblia es raro, en los LXX no aparece. Sólo en el NT es usado en el sentido transitivo. Se encuentra en Mc 15,23: los soldados ofrecen a Jesús vino mirrado, antes de la crucifixión.

El uso antiguo de mezclar vino con mirra es atestiguado también en otras fuentes. No obstante el sabor amargo, se obtenía un vino perfumado de particular exquisitez. (cf. también el vino aromado del Ct 8,2. Los romanos sostenían que el vino mirrado no era muy inebriativo, por esto gustaba a las mujeres; se sostenía también que la mirra era un conservante del vino). Por consiguiente, es dudoso si en Marcos 15,23 se deba ver una bebida inebriativa que Jesús habría rechazado para morir en plena posesión de sus facultades. Tal vez sea mejor pensar que se trata de un vino que habitualmente era bebido por los soldados que a su tiempo ofrecieron al condenado. De hecho la costumbre judaica de ofrecer al condenado a muerte una copa de vino mezclado con incienso (cf. Pr 31,6-7: "para que se confunda su mente". Con esta finalidad se había formado en la ciudad santa una especie de confraternidad de mujeres aristocráticas, encargadas de preparar tales pociones, Sanhedrin 6,43a), no constituye un paralelo de Mc 15,23, puesto que se trata de soldados romanos y no de mujeres judías; es más, el vino era mezclado con incienso y no con mirra como en este caso. Mientras Lucas y Juan no tienen un pasaje corres-

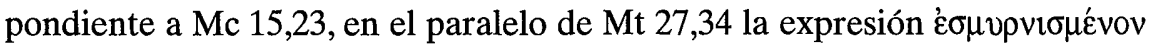
es sustituida por ốvov $\mu \varepsilon \tau \grave{\alpha} \chi 0 \lambda \hat{\eta} 5 . . .=$ "vino con hiel". Este cambio depende tal vez de Mc 15,36 o del Sal 69,22, lo que indica que también Mateo no habría pensado en una bebida inebriativa ${ }^{36}$. También es posible, según J. Gnilka ${ }^{37}$, que el rechazo de Jesús a tomar la bebida que le ofrecen signifique en referencia al texto del libro de los Proverbios que Jesús no es un consagrado a la muerte; o mejor, que la negación de Jesús a beber el fruto de la vid está en directa relación de Mc 14,25, es decir, que Jesús la bebería solamente en el reino de Dios, y este beber tenga conexión con su propia muerte (cf Mc 10,3839) como inicio del reino de Dios ${ }^{38}$.

36. cf. W. MichaELIS, " $\sigma \mu \nu \rho v i \zeta \omega ”, ~ G L N T$, Vol. XII, 673-674.678-680.

37. cf. J. GNILKA, Marco, 882.

38. cf. B. EsCAFFRE, "La mort de Jésus et la venue du royaume dans l'evangile de Marc", EstBib, 337 . 
- v. $24 \beta \alpha ́ \alpha \lambda \lambda \omega$, el sentido en el que viene usado este verbo en el NT es el transitivo en cuya acepción se indica el movimiento violento del arrojar, echar o del golpear. En la traducción de los LXX traduce el verbo נִִָּ en la forma Hifil (cf. 1 S 14,42; Is 34,17; Ez 47,22; 48,29; Jon 1,7; etc.). Así es como viene usado en Mc 15,24. Al verbo le sigue el sustantivo $\kappa \lambda \hat{\eta}$ pov ${ }^{39}$.

- $\kappa \lambda \hat{\eta} \rho{ }$, , en el ambiente griego significa fundamentalmente la suerte. En particular, $\kappa \lambda \hat{p} \rho \varsigma_{S}$ por un lado indica la suerte, con la cual se efectúa el sorteo y el acto del sorteo, por otro lado el lote de terreno asignado mediante el sorteo. J.H. Friedrich ${ }^{40}$ matiza el significado del concepto diciendo que esta suerte, tanto en griego como en hebreo, es la decisión de la Deidad, independientemente de la influencia humana, que se recibe como oráculo para proceder a la elección de una persona, a la legitimación de la distribución de tierras, o en el caso de pleitos. En Israel el único oráculo permitido era el oráculo que se obtenía echando suertes (cf. Dt 18, 9-14; Nm 27, 21ss.).

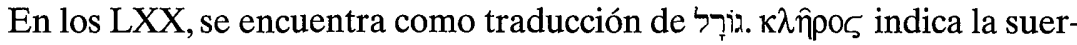

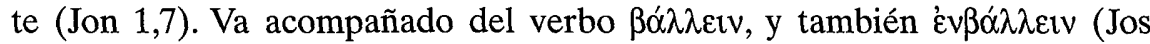
$18,10)$ mientras para indicar una decisión dejada a la suerte se puede encontrar locuciones como "y llegó la suerte a la tribu de los hijos de Benjamín..." (Jos 18,11) o "...echemos a suertes para saber por culpa de quién nos ha venido este mal..." (Jon 1,7). En particular el echar a suertes es un acto del vencedor en la distribución del botín (J1 4,3; Na 3,10; Si 37, 8, y sobre todo Sal 22 (21),19 "Se repartieron entre sí mis vestiduras y sobre mi túnica echaron a suer$t e$ ". A través de la suerte se manifiesta la voluntad de Dios, tanto en la repartición del territorio de Canaán ( $\mathrm{Nm} 26,52 \mathrm{ss})$, como en la asignación del servicio en el templo (I Cro 25,8ss; 2 Esd 20,35); igualmente se confía a la suerte el destino fijado por Dios (Is 34,17; Est 10,3).

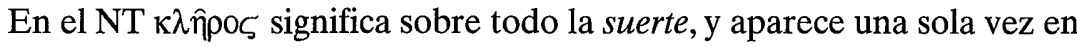
la narración de la Pasión (Mc 15,24par) 41, aquello que en el lenguaje poético del AT expresa una condición de completa sujeción e impotencia (Sal 22,19). Significa la total derrota de Jesús antes sus enemigos. Han vencido aunque momentáneamente.

- v. $26 \beta \alpha \sigma \imath \lambda \varepsilon v ́ \zeta$, la acepción común de este sustantivo en el ambiente griego era para indicar a aquel que ejercitaba en la vida la función de soberanía legítima, que casi siempre era hereditaria y conectada a una función

39. cf. F. HAUCK, " $\beta \alpha \dot{\alpha} \lambda \lambda \omega ", ~ G L N T$, Vol. II, 35-36.

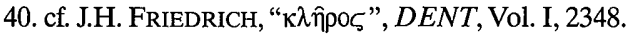

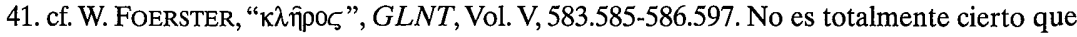
este término aparece solamente en los relatos de Pasión, también se puede encontrar en Hch 1, 17.26;8, 21;26,18; $\mathrm{Col} 1,12 ; 1 \mathrm{Pe} 5,3$, unas veces significando suerte y otras herencia. 
sacra. Se cree que originalmente este término era un préstamo de una lengua

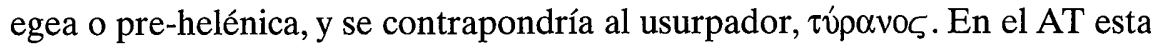
función se expresaba con el término palabra común a todas las lenguas semíticas; el origen primigenio del término es dudoso. Podía ser el de posesor o el de árbitro. Sirvió también para expresar la realeza de YHWH. El uso de מֶל como epíteto de Dios es probablemente protosemítico.

En el NT $\beta \alpha \sigma \imath \lambda \varepsilon v ́ \zeta$ puede designar la realeza, sea de la divinidad, sea de los hombres, sea de los seres intermedios. Desde un punto de vista teológico es importante sobre todo la atribución, estrictamente unida al uso veterotestamentario y judaico, del título de rey a Dios y a Cristo, en contraposición a la realeza de los hombres. Tanto es así que la realeza de Cristo para el NT es un dato obvio y natural. En su cualidad de Mesías es en primer lugar $\beta \alpha \sigma$ -

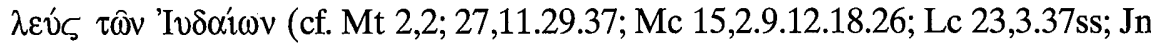
$18,33.37 .39 ; 19,3.14 \mathrm{ss} ; 19,21$ ), definición usada con diversas intenciones. Mientras un contemporáneo neutral como Pilato se limita a repetirla como un elemento de acusación presentada por los judíos, para los fariseos y saduceos, unidos en la obstinada aversión a Jesús, constituye la pretendida blasfemia de un falso Mesías. La masa fluctuante, a la cual pertenecen los discípulos acogidos por Jesús, quisieran hacer de él el "rey de los judíos" temporal y político, malentendiendo el verdadero sentido de la realeza mesiánica de Jesús. Para expresar adecuadamente el carácter mesiánico de la realeza de Cristo en la fórmula "rey de los judios" el genitivo plural debería ser sustituido por el sin-

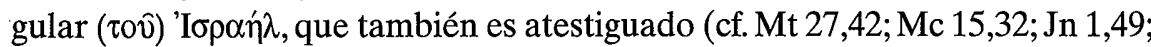
12,13) ${ }^{42}$. En todo caso cuando Marcos usa el término $\beta \alpha \sigma \imath \lambda \varepsilon v ́ s(15,26.32)$ para indicar la inscripción puesta sobre la cruz de Jesús y cuando la pone en boca de los sumos sacerdotes y de los escribas, no es precisamente para acreditar el mesianismo de Jesús, sino al contrario para desacreditarla, un descrédito que después se convierte en verdad con la confesión del Centurión (cf. Mc 15,39b).

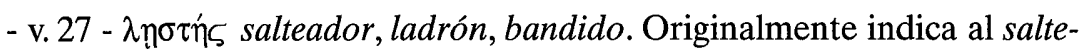
ador; deriva del verbo $\lambda \eta^{\prime} i \xi o \mu \alpha 1$, llevarse como presa o botín, de los sustantivos

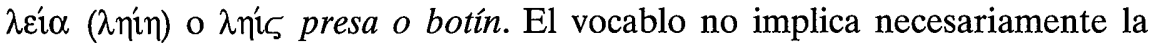
negación de la probidad; por tanto puede indicar también al soldado regular o al mercenario, porque en la antigüedad estos tenían derecho al botín, en este sentido en los LXX indica al soldado enemigo (Jr 18, 22). Sin embargo, siempre se ha usado sobre todo en los autores clásicos en sentido malo. Así sucesivamente sirvió sobre todo para indicar al salteador de cualquier tipo (sea

42. cf. K.L. SCHMIDT, “ß $\alpha \sigma \imath \lambda \varepsilon v ́ \zeta ”, ~ G L N T$, Vol. II, 133-134.144-145.170-171. 
saqueador, ladrón, o pirata), pero también indicaba al soldado indisciplinado; en todo caso está siempre presente la idea de prepotencia en el apropiarse de cosas que pertenecen a otros. En este sentido se distingue $\lambda \eta \emptyset \sigma \tau \eta^{\prime} \zeta$ de $\kappa \lambda \dot{\varepsilon} \pi \tau \eta \zeta$ que es robar secretamente, pero se pueden usar como sinónimos.

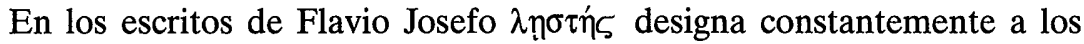
zelotas, aquellos que han dedicado la propia vida a la lucha armada contra la ocupación romana y todos aquellos que la favorecen, la aprueban o la soportan y, que a fin de liberar la nación están listos hasta para donar la propia vida. La causa por la cual luchaban era de tipo político y mesiánico. Ellos tenían un cierto respaldo popular. A estos zelotas los romanos los penalizaban con la cruz, no por ser delincuentes comunes sino porque eran rebeldes a nivel político, un movimiento ilegal. Otro motivo para llamarles $\lambda \eta \emptyset \sigma \tau \alpha i$ era porque no tenían una cohesión interna y externa, tenían varios jefes, como varios grupos, donde los fines personales no estaban ausentes. Por tanto, los zelotas según Josefo era un movimiento que se había equivocado y manchado la matriz religiosa de la liberación del pueblo judío, donde ciertamente el único rey era el Señor. Es más, después de la rebelión de Judas Galileo ( 6 d. C.), a quien se tiene como el fundador de los zelotas la época donde verdaderamente actuaron los zelotas, fue en la rebelión que trajo consigo la destrucción del templo (66-70 d. C.). Al parecer la época de Jesús fue totalmente pacífica 43.

La literatura rabínica también adoptó este término para designar tanto a los zelotas como a los bandidos comunes. Igualmente estos testigos coinciden con Josefo al señalar que se les castigaba con la cruz, que era un suplicio romano. Es posible que conforme pasaba el tiempo los zelotas hayan transformado el nombre de $\lambda \eta \emptyset \tau$ ń ra rabínica el zelotismo era también un movimiento equivocado que proclamaba su lucha contra el estado pagano en nombre de Dios.

En el NT en 2 Co 11,26, se usa el término para designar a los bandidos y en Mt 21,13, significa ladrones, como en Mc 11,17, cuando la purificación del templo (cf. Is 56, 7; Jr 7, 11). En Lc 10,30.36 con la palabra salteadores, en opinión de K.H. Rengstorf ${ }^{44}$, Jesús quería referirse a los zelotas, toda vez que los zelotas no mataban a los judíos; se servían solamente de los viajeros para procurarse medios de subsistencia; e igualmente en el episodio que se narra a partir de Mt 22,15ss. se habría pedido a Jesús una toma de posición de frente al movimiento zelota. En suma Jesús con estas respuestas habría deslindado su posición respecto de los zelotas, es decir, una total desaprobación.

43. Esa es la conclusión de H. Guevara, Ambiente político del pueblo judio en tiempos de Jesús, 1985, 259, después de analizar los libros de Flavio Josefo (Guerras Judías y Antigüedades Judías).

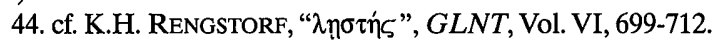


Por lo demás, resulta claro que el zelotismo era un movimiento emparentado con el mesianismo, y no es extraño que se sospechara que Jesús fuera un jefe zelota. Esto se puede encontrar en Mt 26,55; Mc 14,48, que pone en boca de Jesús: “ ¿como contra un bandido salisteis con espadas y garrotes a prenderme?". Más adelante en el proceso se pone a Jesús a la misma altura del sedicioso Barrabás (Mt 27,15ss; Mc 15,6ss), así se habría tomado tanto a Jesús como a Barrabás como dos jefes de distintas bandas de zelotas.

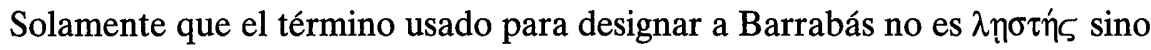

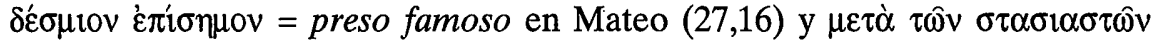
$\delta \varepsilon \delta \varepsilon \mu \varepsilon^{\prime} v{ }^{\prime}=$ con los presos encarcelado en Marcos $(15,7)$. Resulta débil una argumentación que equipare a Jesús con los zelotas. Ni siquiera al mismo Barrabás se le puede atribuir esta categoría. Solamente hay que llegar al v. 27 de Marcos y el paralelo de Mt 27,38, para encontrar el término $\lambda \eta \emptyset \tau \eta \dot{\zeta}$. Lo cual indica que hay que ir por otro camino para lograr una interpretación no tendenciosa.

Que se haya tomado a Jesús como un zelota, puede ser cierto, mas no porque se haya preferido liberar a Barrabás y crucificarle a él. Lo que sucedió en la purificación del Templo Mc 11,17 fue una acción profética de Jesús, pero más que profética fue mesiánica, si bien velada, secreta como lo presenta Marcos, pero que se dará plenamente a conocer en Mc 14,61-62 en su respuesta al Sumo Sacerdote. El camino de Jesús es distinto al de los zelotas, aunque en este caso se entrecruzan porque Jesús da a sus acciones un carácter

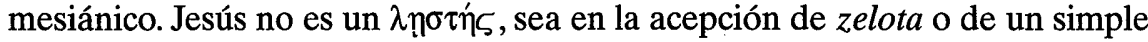
salteador. Al contrario, los denuncia (Mc 11,17). En Mc 14,48, las palabras de Jesús corresponden a una legítima defensa de su propia dignidad ${ }^{45}$, porque se le pone a la misma altura de los salteadores, se le trata como tal, es arrestado como tal, mientras estaba orando (Mc 14,32ss) y no estaba perpetrando una fechoría. Sólo más adelante, cuando es crucificado se puede constatar que, justamente aquello que Jesús no afirmaba de sí mismo, se lo atribuyen los romanos al condenarlo como un rey fracasado, uno de los tantos de la lista de los pretendientes políticos vencidos. Para los sumos sacerdotes será un rey falso, un profeta mentiroso con pretensiones mesiánicas. Sin embargo para los discípulos de Jesús, este hecho de haberlo crucificado entre dos ladrones será el inicio de un nuevo mesianismo. No se sabe con certeza si se trata de dos salteadores comunes o de dos zelotas ${ }^{46}$, (contra R. Pesch que afirma que se trata de dos zelotas), ni se sabe si estaban emparentados con Barrabás. El texto no da pie para tal aseveración. Lo evidente es que la vida de Jesús termina como

45. cf. V. TAYLOR, op. cit., 464; J. GNILKA, op. cit., 817.

46. cf. R. PESCH, art. cit., 710. 
la de los fracasados, de los vencidos por la historia, muere como cualquier bandido ${ }^{47}$.

- v. 29. $\beta \lambda \alpha \sigma \phi \eta \mu \varepsilon \dot{\varepsilon} \omega$, blasfemo. Mientras $\beta \lambda \alpha \sigma \phi \eta \mu i \alpha 48$ como "nomen actionis" indica siempre el acto de blasfemar; $\beta \lambda \alpha \sigma \phi \eta \mu 0 \zeta$ puede designar tanto un modo de ser como un acto. En la literatura griega $\beta \lambda \alpha \sigma \phi \eta \mu$ í $\alpha$ indica el discurso calumnioso, es decir, el uso de la palabra para dañar a alguien, en contraste con la $\varepsilon \dot{\phi} \emptyset \mu^{\prime} \alpha$. Indica también la expresión más virulenta de la burla y del ultraje personal. En los LXX no se da un correspondiente preciso y estable con el original hebreo, indica siempre una ofensa personal dirigida directamente o indirectamente a Dios, como puede ser también la negación de su potencia salvífica (Is 52,5 ).

El NT concibe la blasfemia sustancialmente como un ultraje al poder y a la soberanía divina. Para los evangelistas son blasfemos tanto los soldados que se burlan de la virtud profética de Jesús (Lc 22,64ss), como los espectadores de la crucifixión (Mc 15,29 y Mt 27,39), como el ladrón impenitente (Lc $23,39)$, cuando desafían burlonamente a Jesús para que muestre su naturaleza de Hijo de Dios.

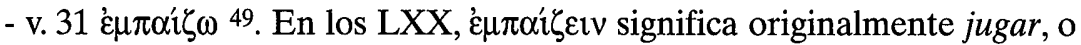
saltar sobre; del cual deriva el sentido de tomar el pelo a alguno, burlarse, reirse, befarse, ilusionar, engañar, hacer escarnio a alguno. La manera de expresar el desprecio y la desestima de los hombres y, según los casos, también del mundo, de las criaturas y hasta del mismo Dios, sea hablando irónicamente o con desprecio, sea escarneciendo, ofendiendo, haciendo gestos con la nariz, rechiflando, pifiando, moviendo la cabeza (cf. 4 Re 19,21; Jb 16,4; Si 12,18; 13,7). Puede hacer alusión también a ciertos juegos de niños o de adultos 50 que eran practicados en ciertas ocasiones en el mundo griego, como parece ser el caso que se menciona en Lc 22,63-64, donde los soldados, como si estuvieran jugando, se burlan de Jesús vendándole y haciéndole preguntas para que él adivinara quién fue el que le golpeó.

En la narración de la Pasión (Mc 15,16-20; Mt 27,27-31) se encuentra una descripción especial de las burlas sufridas por Jesús infringidas por los soldados. Mas tarde reaparecen las burlas en todos los sinópticos en la escena de la crucifixión (Mc 15,31; Mt 27,41; Lc 23,36). El sentido que toma este verbo 51

47. cf. X. Pikaza, op. cit., 409-410.

48. cf. B.W. BEYER, " $\beta \lambda \alpha \sigma \phi \eta \mu \varepsilon \omega ", ~ G L N T$, Vol. II, 279.281.287.

49. cf. G. BERTRAM, "غ่ $\mu \pi \alpha i \zeta \omega "$, GLNT, Vol. IX, 204.208-209.217.219-220.

50. cf. D.L. MILLER, "EMIAIZEIN: Playing the Mock game (Luke 22: 63-64)", JBL, 309-313.

51. cf. F.G. UNTERBMAIR, “ $\varepsilon \mu \pi \alpha^{\prime} \zeta \zeta$ ”, DENT, Vol. I, 1359-1361. 
cuando viene usado en la narración de la Pasión es el de escarnecer, como sucede en los LXX (Gen 39,14; 2 Cro 36,16), aunque también ocurre con la misma raíz para significar jugar (cf. Sal 103,26; Jc 16,27).

- v. $34 \beta$ oó $\omega$, significa gritar, llamar. Desde el punto de vista teológico es importante sobre todo el uso de ßoóc y la familia de términos con la misma raíz, sirve para indicar el grito de dolor elevado hacia Dios por el oprimido y el atormentado. En Ex 2,23; Dt 26,7; Jc 10,12; 2 S 22,7ss; Ne 9,28; Sal 18,7; 69,4, se expresa el grito del perseguido que espera venganza. Aunque también puede expresar el grito de los que se sienten impotentes, como en Lc 9,38 expresa los gritos que daba el padre del muchacho epiléptico; en Lc 18,7 manifiesta el clamor de las oraciones que los elegidos dirigen a Dios; en Lc 18,38 , indica los gritos de un ciego.

Diverso significado tiene el grito de Jesús en la cruz en Mc 15,34. Una vez más es el elegido de Dios que gime abandonado al furor de los impíos; pero su oración no tiene que ver con sus enemigos, sino solamente con Dios. Es el clamor del crucificado dirigiéndose al Padre. El hijo del hombre ha tocado el fondo del dolor humano, se siente abandonado por Dios, y este acceso de sufrimiento le saca este grito tan humano en el cual se concentran todas las últimas energías del moribundo. Pero este éßంєбєv no es una invocación de ayuda o de venganza, sino una invocación del anhelo de la presencia de Dios 52. Además, con la particularidad que se ha señalado arriba, que el verbo ßoó $\omega$, es usado en Mc solamente en dos ocasiones, cuando se evoca una cita del profeta Isaías (40,3), para referirla a Juan el Bautista llamando a la gente al arrepentimiento ${ }^{53}(1,3)$ y en boca de Jesús $(15,34)$.

- v. $35 \phi \omega v \varepsilon ́$, indica la emisión de un sonido o de una voz producidos por instrumentos musicales, animales u hombres. Este verbo es raro en los LXX (se usa

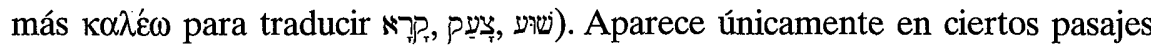
para traducir vocablos hebreos o arameos, indicando el sonido de la trompeta (Am 3,6; 1 M 9,12) y el gritar de animales (Is 38,14; Jr 17,11; So 2,14, etc.). En el NT no aparece en las cartas. Significa el hablar en alta voz o el gritar de hombres, ángeles o demonios y puede ser reforzado por la expresión $\phi \omega v \eta ̣ ̂ \varepsilon \gamma \alpha \dot{\alpha} \lambda \eta n(\mathrm{Mc} 1,26$;

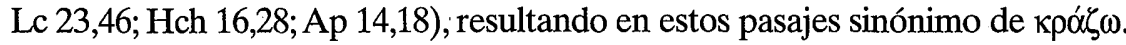

Probablemente el grito que Jesús emitió en la cruz y con el cual, según algunos judíos, llama a Elías fue entendido como invocación a aquel que salva y trae salvación (Mc 15, $35 ; 10,49){ }^{54}$.

52. cf. E. STAufFer, “ßoów”, GLNT, Vol. II, 292.296-297.

53. cf. H. BALZ- G. SCHNEIDER, "ßoó $\omega$ ", DENT, Vol. I, 669-670.

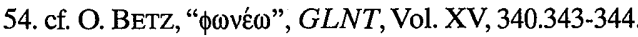


- v. $36.46 \kappa \alpha \theta \alpha \uparrow e^{\prime} \omega$, el verbo que desde Homero aparece frecuentemente, se encuentra en el ambiente pagano del mundo griego con cuatro significados: a) descolgar; b) demoler; c) vencer, destruir, condenar a un adversario, a una ciudad; d) destronar. En el NT se encuentra el primer significado para expresar la deposición de la cruz, Mc 15, 36 (cuando Jesús estaba aún con vida); y en Mc 15, 46; Lc 23, 53; Hch 13, 29 (cuando Jesús había ya expirado) ${ }^{55}$. De las nueve veces que aparece este verbo en NT, en Marcos éstas son las dos únicas ${ }^{56}$, es decir, solamente usó este verbo en el contexto de la Pasión de Jesús, para expresar el bajar de la cruz a Jesús.

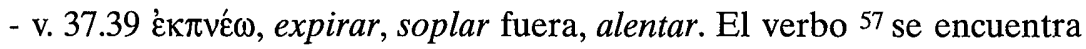
con el significado del exhalar (la vida). En el NT aparece solamente en Mc 15,37.39 (cf. Lc 23,46). El vocablo revela la primitiva concepción de la vida que en el momento de la muerte el espíritu deja el cuerpo yéndose con el respiro.

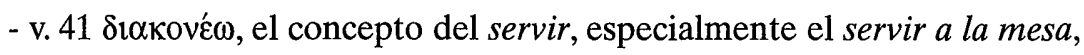
en griego se expresa mediante varios verbos, entre los cuales se encuentra el presente verbo. Respecto al mundo griego la posición de Jesús en cuanto al servir es totalmente nueva. La nota determinante es que en el servicio él ve por añadidura (partiendo del precepto del amor veterotestamentario hacia el prójimo, conectándolo con el precepto del amor a Dios) el comportamiento que hace del hombre un discípulo suyo (Mt 4,11;8,15;20,28;25,44; 27,55; Mc $1,3.31 ; 10,45 ; 15,41 ;$ Lc 4,$39 ; 8,3 ; 10,40 ; 12,37 ; 17,8 ; 22,27 ;$ Jn 12,2.26).

Sin embargo, también sigue presente en el NT el propio significado del servir en la mesa (cf. Lc 17, 8). Junto a la connotación anterior, el NT recoge un ulterior significado de ser servicial. A veces este alejamiento del concepto del servicio en la mesa es claramente reconocible cuando se relata el servicio de las mujeres que acompañaban a Jesús (Lc 8,3; Mt 27,55; Mc 15,41). Lo que

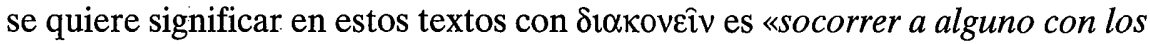
propios bienes» 58 .

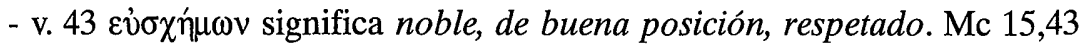

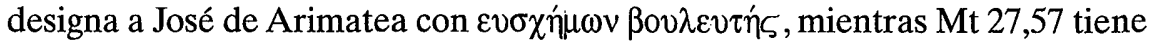
un significado más limitado $\pi \lambda 0 v 0105$, y Lc 23,50ss parece haberlo referido a

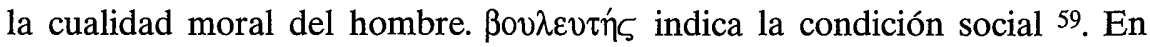

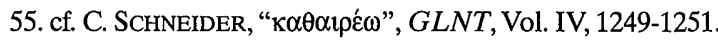

56. cf. H. HüBNER, "к $\alpha \theta \alpha \iota \varepsilon^{\omega} \omega ", D E N T$, Vol. I, 2092.

57. cf. E. SCHWEIZER, “'́к $\pi v \varepsilon ́ \omega ”, ~ G L N T$, Vol. IX, 1101.

58. cf. B.W. BEYER, “ $\delta 1 \alpha K o v \varepsilon ́ \omega ”, ~ G L N T$, Vol II, 951.957-958.961.

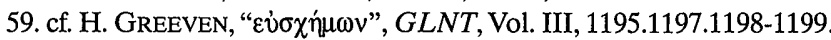


general con este término ${ }^{60}$ se quiere indicar en el NT a personas estimadas,

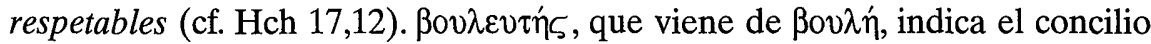
entendido como institución política y sus deliberaciones, aunque $\beta 0 v \lambda \eta ́$ también significa: voluntad, decisión, determinación, el parecer de alguno 61 . Por

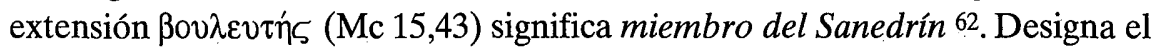
cargo oficial que desempeñaba José de Arimatea ${ }^{63}$, lo que difiere de Mt 27,57 y Jn 19,38 donde se le presenta como $\mu \alpha \theta \eta \tau \dot{n} \zeta=$ discípulo.

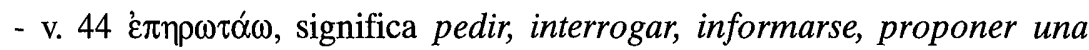
cuestión. '̇ं sinópticos recurren a la perífrasis (Mc 7,5.17; 8,23; 9,28; 10,2.17; 12,28; 13,3;

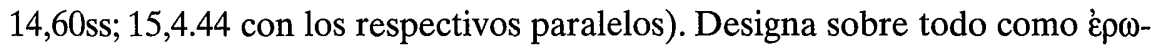
$\tau \alpha \alpha \omega$ con el cual frecuentemente se alterna en los pasajes paralelos de los sinópticos, el preguntar en general. A veces parece indicar una pregunta insistente (Jn 18,7). También forma parte de la instrucción judicial (Mc 14,60), igualmente denota la indagación o la verificación (Mc 15,44; Hch 23,34) ${ }^{64}$.

60. cf. P. FIEDLER, “عن่ $\chi \eta \mu \omega v ”, ~ D E N T$, Vol. I, 1687-1688.

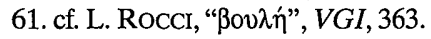

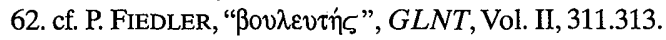

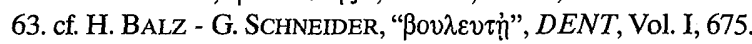

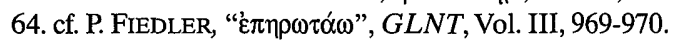




\section{PRIMERA SUBSECUENCIA: Crucifixión (v. 21-32)}

Compuesto por dos pasajes.

1.1. PRIMER PASAJE: Crucifican al "Rey de los Judíos" (v. 21-28)

Compuesto por tres fragmentos.

\begin{tabular}{cc}
\hline$=21$ Y obligan a uno & que pasaba, \\
:: a Simón & de Cirene, \\
$=$ que volvía & del campo, \\
$:$ el padre & de Alejandro y de Rufo, \\
& cruz.
\end{tabular}

$=22$ Y le conducen
:: al lugar
del Gólgota, -que significa-:

:: lugar

del Cráneo.

$=23$ Y le daban vino mirrado, $+24 \mathrm{Y} \mathrm{le}$ pero él no lo tomó. crucifican
* y se reparten
sus vestidos,
- echando a suertes
sobre ellos
* (para ver) lo que cada uno
se llevaría.

$=25$ Era la hora tercia

$=26 \mathrm{Y}$ estaba la inscripción :: «EL REY

+27 Y con él

$::$ a dos salteadores,

$=[28$ Y se cumplió

:: con los malvados cuando le crucificaron.

de su causa escrita encima: DE LOS JUDÍOS».

\section{crucifican}

uno a la derecha y otro a su izquierda.

la Escritura que dice:

fue contado.] 


\subsubsection{COMPOSICIÓN}

\section{a) Primer fragmento: los soldados romanos crucifican a Jesús (v. 21-24a)}

Compuesto por cuatro segmentos, dos bimembres y tres trimembre. El primero es de construcción paralela: $a b / a^{\prime} b^{\prime}$. El segundo es un segmento trimembre de tipo: $A B C$. El siguiente segmento es también trimembre de tipo $A B B$ '. El cuarto segmento es bimembre de construcción paralela. El elemento unificador es el sustantivo "cruz" y el verbo "crucificar" y los sujetos son los mismos (los soldados, cf. 15,16ss) en tres segmentos. Difiere únicamente el segundo segmento donde el sujeto es Simón de Cirene. En los otros segmentos, los soldados son los que: "obligan" a uno que pasaba, "le conducen", "le dan" vino mirrado, y "le crucifican" a Jesús, todos al presente.

\section{b) Segundo Fragmento: el despojo de las vestiduras (v. 24bcd)}

Compuesto por un segmento trimembre de tipo: $A B A^{\prime}$. Son simétricos los miembros extremos a través de los verbos: "repartir" y "llevar" que son correlativos. Además es la parte central del pasaje, con una alusión al Sal 22,19, que según la primera ley de Lund: "El cambio está siempre al centro. El centro puede consistir de una, dos, tres y también de cuatro líneas" 65; en efecto, en estas tres líneas no hay ninguna referencia a la cruz o al hecho del crucificar.

\section{c) Tercer fragmento: los excluidos de la sociedad oficial (v. 25-28)}

Se compone de cuatro segmentos bimembres. Los elementos unificadores son el verbo "crucificàr" y el sustantivo "Escritura". El título "El rey de los judíos" hace de centro en este fragmento. Los verbos sitúan las acciones en el pasado (era, crucificaron, estaba, escrita encima, se cumplió, fue contado), excepto crucifican y que dice, que están en el presente.

Estos tres segmentos, se relacionan en forma paralela: $A B C D E$ $A^{\prime} B^{\prime} C^{\prime} D$ '. En $A A^{\prime}$ aparece un judío de la diáspora y los malvados, en el primer caso se trata de un judío que entra a formar parte de los discípulos de Jesús; en el segundo caso, los malvados de la sociedad oficial, los no discípulos. La relación es de oposición. En $B B^{\prime}$ y en $D D^{\prime}$ aparece cuatro veces la raíz "cruz", en $B D$ como términos finales, en el tercer y segundo miembro respectivamente y en $D^{\prime} B^{\prime}$ como términos finales igualmente pero como parte del primer miembro. Por lo demás indican el tema dominante en el pasaje. Los dos hijos de Simón aparecen como los nuevos discípulos. Uno con nombre griego $=$ Alejandro, el otro con nombre latino $66=R u f o$. Señalan la uni-

65. Citado por R. MEYNET, L'analisi..., 119.

66. cf. J. Mateos - F. CAMAcho, op. cit., 379; R. Meynet, Passion...., 189. 
versalidad de este nuevo Rey. En cambio dos son los salteadores. Ninguno de los dos tiene nombre. Son los no discípulos. El segmento $E$ ocupa el centro, donde Jesús como todo condenado a muerte ${ }^{67}$, tanto en la sociedad romana como en la judía, está desnudo 68 ante los ojos de todos, es despojado de todo hasta de sus vestidos (cf. Sal 22,19). En $C C^{\prime}$ la relación es más abstracta, por un lado le conducen fuera de la ciudad (cf. Lv 24,14ss; Nm 15,35; I R 21,13; Hch 7,58 ) a un lugar elevado "Gólgota", por otro su causa está escrita "encima"; como es un rey frustrado, un rebelde, todo el mundo debe saberlo; a la vista de todos en un lugar alto está el fracasado "Rey de los judíos".

En el primer fragmento los soldados son los ejecutores de las acciones, lo cual sirve como dato histórico. Se cierra con "y le crucifican". En el segundo fragmento siguen actuando los soldados, pero esta vez cumpliendo una parte de la Escritura, la del Sal 22,19. En el tercer fragmento las acciones son narradas en pasado, el dato de la crucifixión está al inicio del segmento, haciendo a su vez tres actualizaciones: una primera precisando la hora de la crucifixión; la segunda informando que eran dos los acompañantes de Jesús en el momento de la crucifixión; y la tercera señalando una vez más el cumplimiento de las Escrituras.

\subsubsection{CONTEXTO BÍBLICO}

Simón de Cirene, un judío de la diáspora ${ }^{69}$, que se convierte en discípulo y es el primero en cargar con la cruz como lo había pedido el Maestro (cf. Mc 8,34), no consta que haya sido discípulo antes de que fuera obligado por los soldados a llevar la cruz en vez de Jesús, después de que todos sus discípulos, llamados previamente (cf. Mc 3,13-19), lo abandonaron (cf. Mc 14,50). No hay ningún discípulo presente en este momento fatal, solamente un extraño junto con los salteadores/malvados (vv.27-28) le acompañan. Para Marcos y su comunidad la familia de Simón de Cirene probablemente era de relevancia, tanto que es el único en mencionar a sus hijos, Alejandro y Rufo (cf. Mt 27,32; Lc 23,26). Juan ni siquiera menciona a Simón (cf. Jn 19,17).

Cirene ${ }^{70}$, era una ciudad importante en el período inicial del cristianismo (cf. Hch 2,10). De allí provenían muchos de los primeros judíos convertidos a la nueva fe, entre ellos algunos notables (Hch 13,1), y son intrépidos en predicar la Palabra (Hch 11,20) a los propios judíos y a los de origen griego,

67. Los romanos practicaban la crucifixión; los judíos por su parte, lapidaban a los condenados a muerte.

68. cf. F.M. URICCHIO - G.M. STANO, op. cit., 627. J. RADERMAKERS, op. cit., 314. 
no obstante la persecución y la dispersión que explotó en Jerusalén después de la muerte de Esteban (Hch 8,1.4). Igualmente en el tiempo de los Macabeos (siglo II a. C.), Cirene contaba con una comunidad notable de los judíos (cf. 1 M 15,23), incluso mucho antes (siglo IV a. C.) constituían una comunidad de más de cien mil judíos, una comunidad de la así llamada diáspora ${ }^{71}$.

"Se reparten sus vestidos", evoca al Sal 22 (21),19: "Se reparten entre sí mis vestiduras y se sortean mi túnica".

"Era la hora tercia cuando le crucificaron", la mención de la hora hay que verla en relación a las otras menciones de la hora en los vv. 33-34. Por ahora basta con evidenciarla.

"El rey de los judíos", es interesante notar que Marcos es el único en traer este título como la inscripción que habrían puesto en la cruz los que crucificaron a Jesús, mientras Mt 27,37 dice: “Éste es Jesús el rey de los judíos”; Lc 23,38: "Éste es el rey de los judíos"; Jn 19,19 testimonia: "Jesús nazareno rey de los judios"; a decir verdad, aún quedando inalterado lo esencial, cada evangelista acusa una tradición distinta, explica una cosa que para él es relevante. Marcos es el más conciso, lo cual no es sinónimo de original o histórico; lo importante de esa inscripción era dar a conocer al público y al pueblo en general la culpa del condenado a muerte 72 e indirectamente lo que en realidad es Jesús. Por lo demás, es el título con que Pilato, en son de burla, comienza a llamar a Jesús, cuando los judíos le presentan para ser juzgado (Mc 15,2.9.12); más adelante, los soldados usan el mismo título para burlarse de Jesús (Mc 15,18).

La mención de los dos salteadores/malvados (vv.27-28), enlaza la narración Marciana de la Pasión con el cuarto canto del Siervo sufriente, Is 53,12c: "y con los malvados (= ó $\left.\mu \alpha p \tau^{\prime} \alpha_{5}\right)$ fue contado". Recuerda además las pala-

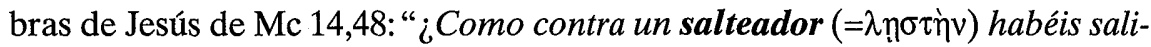
do a prenderme con espadas y palos".

\subsubsection{INTERPRETACIÓN}

“Uno que pasaba", en el original griego el mismo verbo $\pi \alpha p \alpha ́ \gamma \omega=$ "pasar por" Marcos lo usa en un contexto de llamada en otras dos ocasiones $(1,16$;

69. cf. J. GNILKA, op. cit., 881.

70. En tiempos de Jesús era una provincia romana, ya desde el 75 a. C., se sitúa al norte de Africa, hoy Barká o Cirenaica, cf. H. HAAG - A. van den BORN - S. de AuSEJo, "Cirene", DB, 333; H. BALZ - G. SCHNEIDER, "Cirene”, DENT, Vol. I, 2436.

71. cf. F.M. URICCHIO - G.M. STANO, op. cit., 628.

72. cf. J. GNILKA, op. cit., 884-885. 
2,14ab), en ambos casos los llamados cambian radicalmente de vida, se convierten en discípulos de Jesús (cf. 1,17-18;2,14c). Esto es lo que sucedió con Simón de Cirene. Hasta entonces no tenía nada que ver con Jesús, no se dice que Jesús es el que pasa, bien que lo supone el hecho de estar llevando la cruz rumbo al lugar de la crucifixión, se dice por el contrario que era Simón quien pasaba, y se convierte en discípulo suyo; tampoco se precisa ni se sabe cuál era su profesión, pues, la mención de "que volvía del campo", solamente señala que regresaba de las afueras de la ciudad y al cargar con la cruz de Jesús cambia de profesión, se hace discípulo. Jesús no lo llama. Sin embargo, Simón se solidariza con él, cumpliendo con la condición del seguimiento $(8,34)$. El verbo oípw se usa en los dos casos, en la cita anterior y en 15,21 refiriéndose a Simón. Es cierto que Simón fue requerido para llevar la cruz, pero el mismo verbo $\alpha \gamma \gamma \alpha \rho \varepsilon v ́ o v \sigma ı v$, que tiene la connotación del prestar un servicio público, se acopla con otra actitud fundamental de un discípulo de Jesús, el ser servidor, el último de todos, servicial ( Mc 9,35; 10,43.44). Simón de esta manera se convierte en modelo del discipulado ${ }^{73}$, y como se decía arriba al hablar acerca del uso del verbo $\alpha \gamma \gamma \alpha \rho \varepsilon v ́ o v \sigma ı v$, Simón de Cirene también pasa a ser el servidor del nuevo Rey.

"El rey de los judíos", la frase que le antecede contiene una palabra que

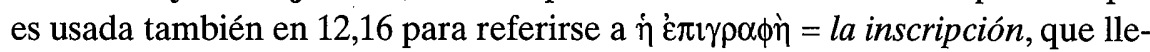
vaba la moneda de los romanos como signo de la realeza del César y el instrumento de su dominio, aquí se usa (la inscripción) para indicar la realeza de Jesús que tiene como instrumento la cruz, símbolo del ofrecimiento de sí mismo, mas es una realeza que no tiene por finalidad el dominio, sino el de comunicar vida ${ }^{74}$. Una realeza que le viene de Dios, no de los que le crucifican, ya que ellos le contaban como un malhechor más, uno que ha pretendido hacerse con el poder, hacerse rey (v. 28) y los que le hacen crucificar como un blasfemo (cf. 14,61-64). Así, irónicamente Jesús es el verdadero rey en oposición a cualquier rey terreno que busca someter a los demás, antes que servir.

"Como una oveja ante los que la trasquilan, está muda, tampoco él abrió la boca", Jesús, ya no habla, primero lo acusaron falsamente, lo azotaron, le hicieron cargar con la cruz, ahora lo crucifican, no se queja, no habla. Es un justo condenado, incomprendido, como uno de tantos de la historia de la salvación (cf. Jr 15,10-21; 18,18-23), pero es el último y el definitivo, que carga con las culpas de los demás. No será necesaria otra oblación (Hb 10,14). Jesús queda clavado en la cruz sin decir palabra, inmolándose por todos.

73. cf. B.K. BLOUNT, "A Socio-Rhetorical analisys of Simon of Cyrene: Mark 15: 21 and Its parallels", Sem, 174.176-177.

74. cf. J. MATEOS - F. CAMACHO, op. cit., 382. 
1.2. SEGUNDO PASAJE: Ridiculizan al "Cristo, Rey de Israel" (v. 29-32)

Compuesto de tres fragmentos.

$$
\begin{aligned}
& =29 \text { Y los que pasaban LE INJURIABAN, } \\
& :: \text { meneando la cabeza } \\
& =y \text { diciendo: } \\
& :: \ll j A h \text { !, el que destruye el Santuario } \\
& : \text { y lo edifica en tres días, } \\
& \text { :: } 30 \text { ¡Sálvate a ti mismo } \\
& \text { + bajando de la cruz!». }
\end{aligned}
$$

\begin{tabular}{cc}
\hline${ }^{31}$ Igualmente también & BURLÁNDOSE \\
$::$ los sumos sacerdotes & entre ellos \\
$::$ con &
\end{tabular}

los escribas,

= decían:

$::$ «A otros

salvó,

:: a símismo no puede salvarse;

+ 32 que baje ahora de la cruz,

$:$ para que veamos y creamos,

:: ¡EL CRISTO, $\quad$ EL REY DE ISRAEL! ».

$=$ También $\quad+$ los que con él

\subsubsection{COMPOSICIÓN}

a) Primer Fragmento: los que pasaban (v. 29-30)

Compuesto de tres segmentos. El primero es un bimembre con cuatro términos, de tipo paralelo: $a b / a^{\prime} b^{\prime}$. El segundo es un trimembre de tipo: $A B B^{\prime}$. El tercero es un bimembre con cuatro términos de tipo paralelo: $a b / a^{\prime} b^{\prime}$.

b) Segundo Fragmento: los Sumos Sacerdotes y los Escribas (v. 31-32abc)

Resultan tres segmentos. El primero y el segundo son trimembres de tipo: $A B B^{\prime}$. El tercero un trimembre de tipo: $A B C$. 


\section{c) Tercer Fragmento: los Salteadores (v. 32de)}

Formado por un segmento bimembre con cuatro términos de tipo paralelo: $a b / a^{\prime} b$ '. El pasaje se caracteriza por verbos que pertenecen al mismo campo semántico: "le injuriaban", "burlándose", "le insultaban". Otro elemento unificador es la raíz "cruz" que aparece una vez en cada uno de los fragmentos. Los verbos sitúan las acciones en el pasado: pasaban, injuriaban, decian, insultaban. Como tres son los fragmentos del pasaje, tres son los grupos que injurian al crucificado: "los que pasaban", "los Sumos Sacerdotes con los Escribas", "los salteadores". Prácticamente al distinguir estos tres grupos, nadie da crédito a Jesús como Salvador, ni los circunstantes, la gente de a pie, la gente común y corriente; ni los jefes religiosos; ni mucho menos los que estaban crucificados con él, como si todos se hubieran puesto de acuerdo o contagiado para injuriarlo, denostarlo y denigrarlo por completo. De tal manera que nadie creyese en él, todo su mensaje y su vida vienen reducidos aparentemente a la nada.

\subsubsection{CONTEXTO BÍBLICO}

Los que pasaban injuriando a Jesús meneando la cabeza, evoca la versión de los LXX a 4 Re 19,21; Jb 16,4; Si 12,18; 13,7; Sal 22,8; 109,25; Jr 18,16; Lm 2,15 , donde el mover la cabeza es un signo de escarnio y desprecio, especialmente el Sal 22,8, donde se usa el mismo verbo kıvé $\omega$. Aquí igualmente Jesús es objeto de escarnio, es ofendido con gestos y palabras.

\subsubsection{INTERPRETACIÓN}

"Meneando la cabeza", como en el Sal 22,8 los que pasan y ven al condenado injustamente le afrentan y hacen mofa de él moviendo la cabeza y recordándole palabras supuestamente dichas por él (el que destruye el santuario y lo edifica en tres días), al menos en Marcos no consta que Jesús hubiese dicho estas palabras (cf. Jn 2,19). Ya sólo el mover la cabeza es una burla. Atribuirle cosas no dichas y pedirle que se salve a sí mismo es aumentar los sufrimientos del crucificado. El descrédito hacia su persona es el resumen de la desaprobación de su mensaje, de su propuesta de salvación, por eso mueven su cabeza; no creen que pueda ser el Rey, el Salvador ni siquiera de sí mismo, menos para el pueblo de Israel. Le piden un signo: que baje de la cruz.

"El Cristo rey de Israel", un rey de Israel era el ungido (= Cristo, de la raíz

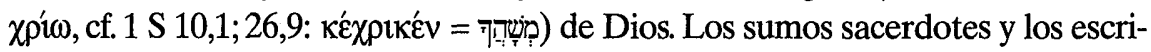
bas que debían haber comprendido viendo a través de sus acciones y sus palabras, que Jesús era el Mesías a quien esperaban desde hace tiempo, también lo desacreditan. Los representantes oficiales de la religión, los intérpretes de las Escrituras quieren ver una señal, un milagro, le piden que baje de la cruz, que se salve 
a sí mismo. Al contrario le toman como un mentiroso, un falso "rey de Israel", por tanto un blasfemo. No obtienen respuesta a sus peticiones, a sus provocaciones, a sus burlas. El silencio del condenado es absoluto, no es él quien debe dar testimonio de sí mismo. El Mesías como el justo del Sal 22,27 espera ser liberado y escuchado por el Señor (Sal 22,30-32). Su causa está confiada al Señor.

"Los que con él estaban crucificados" contado entre los malhechores, ni siquiera ellos, dada su situación, se solidarizan en su dolor, también lo insultaban, no se sabe cuáles fueron esos insultos, como no tienen nombres, tampoco palabras, son actores de segundo orden. Pero al mismo tiempo el insulto de los que le acompañaban a Jesús en el suplicio de la cruz, le hace diferente de ellos. No es del grupo de los $\lambda \eta \eta \sigma \tau \alpha ́$, , está confundido con ellos, pero no es uno de ellos, pues ellos mismos no lo aceptan.

\subsection{EL CONJUNTO DE LA SUBSECUENCIA (v. 21-32)}

21 Y obligan a uno que pasaba, a Simón de Cirene, que volvía del campo, el padre de Alejandro y de Rufo, para que llevara su cruz. $22 \mathrm{Y}$ le conducen al lugar del Gólgota, que significa-: lugar del Cráneo. 23 Y le daban vino mirrado, pero él no lo tomó. 24 Y le crucifican

y se reparten sus vestidos, echando a suertes sobre ellos (para ver) lo que cada uno se llevaría.

25 Era la hora tercia cuando le crucificaron. 26 Y estaba la inscripción de su causa escrita encima: «EL REY DE LOS JUDÍOS». 27 Y con él crucifican a dos salteadores, uno a la derecha y otro a su izquierda. [ ${ }^{28} \mathrm{Y}$ se cumplió la Escritura que dice: con los malvados fue contado.]

29 Y los que pasaban le injuriaban, meneando la cabeza y diciendo: «jAh!, el que destruye el Santuario y lo edifica en tres días, 30 ¡Sálvate a ti mismo bajando de la cruz!».

31 Igualmente también burlándose los sumos sacerdotes entre ellos con los escribas, decían: "A otros salvó, a sí mismo no puede salvarse; ${ }^{32}$ que baje ahora de la cruz, para que veamos y creamos, ¡EL CRISTO, EL REY DE ISRAEL!».

También le insultaban los que con él estaban crucificados. 


\subsubsection{COMPOSICIÓN}

Esta subsecuencia compuesta de dos pasajes, tiene en cada uno de sus pasajes tres fragmentos, el primero: a) vv. 21-24a, b) v. 24bcd, c) vv. 25-28; el segundo: a) vv. 29-30, b) vv. 31-32abc, c) v. 32de. Cada pasaje inicia mencionando a "uno que pasaba" (v. 21a) y a "los que pasaban" (v. 32d), terminan también con la alusión de los acompañantes de Jesús en la cruz (vv. 27-28 y v. 32de).

El tema que relaciona a los dos pasajes es el hecho de la crucifixión que viene mencionado siete veces; cuatro veces en el primer pasaje (v. 21e.24a. 25b.27a) y tres en el segundo (v.30b.32a.e). Por otro lado, cada pasaje lleva un título referido a Jesús: "El Rey de los judios” (v. 26b) y “ ¡El Cristo, Rey de Israel!"(v. 32c). El primero dado por los romanos y el segundo por los jefes religiosos. Se diferencian porque en el primer pasaje los soldados crucifican a Jesús, y en el segundo Jesús es objeto de burlas.

\subsubsection{INTERPRETACIÓN}

"El nuevo Rey", por encima de lo que puedan pensar romanos y judíos acerca de Jesús clavado en la cruz, los primeros como un malogrado rey y los segundos como un falso rey supuestamente ungido por Dios, el reinado suyo se ha iniciado, contra todos los pronósticos adversos. No hace falta la confirmación de las instituciones terrenas. Por un lado ya fue ungido (cf. 14,3) y tiene un primer seguidor judío Simón de Cirene, un servidor real que lleva su cruz (v. 21). Su corte no es de los primeros, sino de los últimos (cf. 10,41-45). Es un reino que se abre a todo el mundo (cf. Sal 22,28). Se puede inferir esto partiendo del hecho de que se mencionan dos nombres con carácter universalista: Alejandro (griego) y Rufo (latino), como los discípulos que siguieron el ejemplo del padre.

Hay detrás de la presentación que hace Marcos un cierto grado de ironía ${ }^{75}$, dado que ni romanos ni judíos aceptan a este rey, sin embargo, la historia de la salvación se escribe aún a costa de la incredulidad de éstos. El reino de Jesús, que es el reino de Dios se establece de la manera menos imaginable. Un reino que se establece en la debilidad, como su fuerza; se instaura en el fracaso y en el desprecio a los ojos de los hombres, mas no a los de Dios (cf. 1 Co 1,18-19.22-25;2 Co 12,9;13,4).

Igualmente las injurias que Jesús recibe como muestra del rechazo de su mensaje, de su reinado, la petición de que se salve a sí mismo, tanto de parte de los que pasan, como de los sumos sacerdotes y los escribas, incluidos los insultos de los que estaban crucificados con él, al final son verdaderas blasfemias, cuando paradójicamente a Jesús le hacen crucificar por blasfemo (cf. Mc 14,61-

75. "It is important to note, [...] that the kingship theme is portrayed ironically by Mark. While spectors and Romans use it in a derogatory manner, Mark suggests that it is the key to realizing the hope immanent in such a tragic situation", cf. B.K. BLOUNT, art. cit., Sem, 175. 
64; Mt 26,64-66). En todo esto resulta que el pretendido rey según los romanos y judíos, es verdaderamente rey según Dios (cf. Mc 15,2; Mt 27,11; Lc 23,3; Jn 18,33-37; Hch 17,7; 1 Co 15,24); el que viene injuriado por blasfemo, por maldito (cf. Lv 24,11-16) por parte de los supuestamente puros, es ciertamente blasfemado (cf. Nm 15,30; Is 52,5; 2 M 8,4; 2 R 19,4.6.22; Hch 6,11), porque un rey es hijo de Dios (cf. 2 S 7,8-16; 1 R 17,11-14;22,9-11;28,6; Sal 2,6-7; 110,1-18).

Otra cosa que resulta irónica es que justamente a través de la cruz, un castigo para los esclavos, para los rebeldes, para los traidores y los sediciosos, la humanidad y la creación entera tienen parte en la redención, en la reconciliación con Dios (cf. Ef 2,14-16; Col 1,20;2,14). En suma, la cruz es el trono de este nuevo rey que comienza a atraer hacia sí a todos los confines (cf. Sal 22,28-30) de la tierra.

\section{SEGUNDA SUBSECUENCIA: El grito de Jesús (v. 33-36)}

Compuesta de dos fragmentos.

\begin{tabular}{|c|c|}
\hline $\begin{array}{l}=33 \text { Llegada la hora sexta, } \\
=\text { sobre toda la tierra } \\
=34 \mathrm{Y} \text { a la hora nona }\end{array}$ & $\begin{array}{l}\text { se hizo oscuridad } \\
\text { hasta la hora nona. } \\
\text { con fuerte voz JESÚS gritó: }\end{array}$ \\
\hline+ «Eloi, Eloi, $\quad$-que significa- & ¿lema sabactaní?», \\
\hline + «iDios mío, Dios mío! & ¿por qué me has abandonado?»». \\
\hline $\begin{array}{l}=35 \mathrm{Y} \text { algunos } \\
=\text { al oírlo }\end{array}$ & $\begin{array}{l}\text { de los presentes } \\
\text { decían: }\end{array}$ \\
\hline$+\ll M i r a$ & llama a Elías». \\
\hline $\begin{array}{l}=36 \text { Alguien, corriendo, y empapando } \\
=\text { sujetándola a una caña, } \\
+\quad \text { «Dejad, veamos }\end{array}$ & $\begin{array}{l}\text { una esponja en vinagre, } \\
\text { le ofrecía de beber, diciendo: } \\
\text { si viene Elías a descolgarle.» }\end{array}$ \\
\hline
\end{tabular}

\subsection{COMPOSICIÓN}

\section{a) Primer Fragmento: Jesús gritó (v. 33-34)}

Este primer fragmento se compone de dos segmentos. El primer segmento es trimembre de tipo: $A B C$; el elemento que les relaciona es la men- 
ción de la hora (33abc). El segundo segmento es bimembre de tipo paralelo: $a b / a^{\prime} b^{\prime}$, el elemento relacionante es la invocación de Jesús en forma de pregunta (v. 34bc), que viene traducido al griego después de la transliteración de la frase probablemente dicha en hebreo. Este segmento ocupa el centro de la subsecuencia. Se relaciona con el primer segmento en tanto que explicita en qué consistió el grito de Jesús (v. 34bc).

\section{b) Segundo Fragmento: los presentes anónimos (v. 35-36)}

Se compone de dos segmentos. El primer segmento es trimembre de tipo: $A A^{\prime} B$. Se relacionan semánticamente a través de los verbos "oír" y "llamar" que pertenecen al ámbito de la comunicación. El segundo segmento es trimembre de tipo: $A A^{\prime} B$. La relación se da a través del mismo sujeto quien "ofrecía de beber" (v. 36a) y quien iba "diciendo" (v. 36b). Por otro lado, ambos segmentos se relacionan en los términos iniciales en tanto que vuelve el mismo pronombre $\tau / 5$, primero al plural algunos (v. 35a) y después al singular "alguien" (v. 36a). Aparece igualmente en los miembros centrales el verbo "decir" (v. 35b y v. 36b). También se relacionan a través del verbo ópóc que aparece dos veces en el último miembro de cada segmento como términos iniciales, haciendo el juego esta vez del singular de la tercera persona "mira" (35b) con el plural de la tercera persona "veamos" (v. 36c).

Ahora bien, los dos fragmentos se relacionan mediante la referencia a la raíz hebrea " $" s=e l$ ", que aparece cuatro veces, dos en el primer fragmento para significar Dios (v. 34b) como término inicial, dos en el segundo fragmento para indicar un nombre propio (v. 35b y 36c) como términos finales. Ambos fragmentos se diferencian debido a que en el primero Jesús es el sujeto principal, y el segundo fragmento los sujetos son los que estaban presentes y alguien de entre ellos.

\subsection{CONTEXTO BÍBLICO}

La mención de la oscuridad (v. 33a) que evoca Am 8, 9 en la versión de los LXX: "haré ponerse el sol a mediodía... cubriré la tierra de tinieblas", aludiendo al día de YHWH (cf. Am 5, 18-20), realiza un paralelo evidente, pues Mc 15,33 describe que a la hora sexta, es decir al mediodía sucedió que "se hizo oscuridad sobre toda la tierra". Otros textos con las mismas reminiscencias son: So 1,$15 ; \mathrm{Jl} 2,10-11 ; 3,3-4 ; 4,15-16 ; \mathrm{Jb} 5,14$. Igualmente, aquí la hora sexta, que va seguida por la referencia de la hora nona (v. 34a) hay que verla en relación con la indicación de la hora tercia (v. 25), para encontrar su sentido teológico.

Las palabras del grito de Jesús (v. 34 bc) retoman el Sal 22,2: "Dios mío, Dios mío ¿por qué me has abandonado?”. En este caso es una cita textual del Salmo, las palabras son exactamente las mismas. 
La bebida ofrecida a Jesús (v. 36a) para que la bebiera rememora al Sal 69, 22, que en la versión de los LXX está expresado con el mismo término

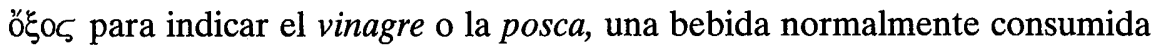
por los soldados o por los jornaleros. Consistía en un vino diluido, de sabor agrio ${ }^{76}$. Esta bebida es distinta a aquella del v. 23a, que es un vino mirrado, de la que no consta de si Jesús la bebió o no.

\subsection{INTERPRETACIÓN}

Las tinieblas, una vez que se cumplieron las tribulaciones que debía sufrir el Hijo del hombre (cf. 8,31; 9,30-31; 10,33-34), los padecimientos del inocente condenado injustamente es acompañado de un signo: la oscuridad 77 . Le escupieron $(14,65)$, le azotaron $(15,15)$, se burlaron de él $(15,29-32)$, después de tres horas de haber sido crucificado, vienen las tinieblas que connotan pavor y por medio del cual Dios habla y enjuicia (cf. Dt 4,10-11;2 M 3,2428 ; Is $8,21-22$; $50,1-3 ; \mathrm{Jr} 13,15-17$; J1 2,1-2; Am 5,8.20; So 1,14-15) aquí las tinieblas se prolongaron por otras tres horas. La intervención de Dios en este caso es incontestable. Sea que haya sido una cosa regional, sea que haya sido sobre toda la tierra, es un signo tradicional del juicio de Dios. El aparente triunfo de los enemigos del justo, el poder religioso y el poder civil, los primeros representados por los Sumos Sacerdotes y los Escribas (Mc 14,1), los segundos por Pilato y sus servidores, los soldados (15,15-16), comienza a derrumbarse. El juicio de Dios se hace presente, no es el justo quien debe demostrar que era inocente (cf. Am 8,9-10).

"Llegada la hora sexta se hizo oscuridad sobre toda la tierra", es el segundo período de tiempo que se menciona; primero, fue: "Era la hora tercia cuando le crucificaron" (v. 25), después vendrá: "Y a la hora nona con fuerte voz Jesús gritó" (v. 34a). Tres períodos de tiempo que según J. Gnilka no son la simple indicación del tiempo, como quisieran M. Lagrange y J. Schmid ${ }^{78}$, y que la comunidad primitiva no conocía aún un tiempo de oración a la hora sexta ${ }^{79}$, lo que hay que entender dado el contexto de elementos apocalípticos (la oscuridad, el grito de Jesús, incluidos los mismos períodos de tiempo), sobre todo en las dos últimas alusiones de la hora, es que Marcos "valora la crucifixión de Jesús como un acontecimiento dispuesto por Dios, que debe ser

76. cf. J. RADERMAKERS, op. cit., 315.

77. Para tener una información detallada sobre la historia de la interpretación de las tinieblas a lo largo de la historia del cristinianismo, véase: R.M. GRÁNDEZ, "Las tinieblas en la muerte de Jesús. Historia de la exégesis de Lc 23, 44-45a (Mt 27, 45; Mc 15, 33)", EstBib 47, 177-223. Consúltese especialmente las páginas: 219-223.

78. Citados por J. GNILKA, op. cit., 884.

79. Ibid., 884 . 
contemplado en el contexto de los acontecimientos del final" ${ }^{80}$. Pero la posición de J. Gnilka ha sido refutada por S. Légasse, quien cree que la delimitación de las horas es "una alienación con la oración cotidiana de los cristianos. [...] algo que no está de acuerdo con el uso judio de la época, sino que se inspira en el Antiguo Testamento (Sal 55,18; Dn 6,11), está prescrito en la Didaché $(8,3)$ " 81 . Ésta delimitación tiene ecos en .Hch 3,1; 10,3.9.30. La segunda postura parece ser la más aceptable.

"Jesús gritó", antes de ser una exigencia de venganza, es una oración confiada de aquel que tiene su seguridad en el Señor: "Dios mío, Dios mío, ¿por qué me has abandonado?". Expresa la esperanza de los que son conscientes de no haber ofendido al Señor, sino que debe sufrir, se pone en las manos del Dios justo que no abandona al que lo invoca (Sal 9,11), como reza todo el Salmo 22 (cf. Sal 13;16;17;31;69; 91). Dicho Salmo, junto con los otros, no se quedan en el lamento ${ }^{82}$ sino que manifiestan la confianza y la esperanza en Dios que salva a los que le invocan (cf. Sal 22;4-6) ${ }^{83}$. La salvación no se hace esperar, pues, al final del Salmo 22 se canta el triunfo (vv. 23-30). El triunfo de Jesús está por llegar. Cierto que aquí, el abandonado y despreciado por los hombres, experimenta también el abandono de Dios, mas no permanece callado, rompe el silencio que había iniciado en 15,5, para invocar a ese Dios que pide y decide todo (cf. 14,36). Jesús, se lamenta pero no abandona a Dios. Es su humanidad que se resiste a creer todo lo que está sufriendo. Aún confía en el Señor por eso le invoca. Con este grito, se rompe igualmente el período de las tinieblas y se prepara un nuevo acontecimiento. En el fondo Dios no lo había abandonado del todo. De otra manera no se explican las tinieblas. Además, está el hecho de la mención del nombre de Jesús (v. 34), como piensa L. Caza ${ }^{84}$, en otras ocasiones cuando Marcos menciona el nombre de Jesús es para señalar una declaración importante (cf. Mc 14,6.18.27.30.48.62;15,1-2.34), o un momento determinante en la narración de la pasión (cf. 14,53.55.60; 15, 1.15.37.43), de esta manera el grito de Jesús ubicándose en la subsecuencia central de la secuencia que está siendo analizada adquiere relevancia sin igual, en la medida en que Jesús está acercándose a la muerte, su grito es de un abandono total en las manos de Dios.

80. Ibid., 884 .

81. S. LÉGASSE, La historia, 119.

82. cf. J.H. REumanN, "Psalm 22 at the Cross. Lament and Thanksgiving for Jesus Christ", Interp, 18.58; J.R. SCHEIFLER, "El Salmo 22 y la crucifixión del Señor", EstBib, 69-70; L. AlONSO SCHÖKEL - C. CARNITI, Salmos I, 452; G. RAVASI, I libro dei Salmi. Commento e attualizazione I, 101-102.

83. cf. L.R. FISHER, "Betrayed by Friend. And expository of Psalm 22", Interp, 36.

84. cf. L. CAZA, "Le relief que Marc a donné au cri de la croix", ScEsp, 172. 
Los circunstantes, no comprenden lo que está ocurriendo o no quieren comprender. Ellos, equivocada o intencionadamente interpretan, que con su grito Jesús está.llamando al profeta Elías ${ }^{85}$ para que le socorra (cf. 1 R 17,924) dada la creencia popular de que Elías salvaba a los justos que sufrían. Por otro lado, no viene explicado quiénes sean estos algunos, si los soldados o los judíos que observan al crucificado en su sufrimiento. Probablemente en esos algunos hay que identificar a los judíos ${ }^{86}$, a los que pasaban ${ }^{87}$, o a los mismos sumos sacerdotes y escribas (v. 31). Si aquella gente entendió debidamente que Jesús invocaba a Dios en su grito (v. 34), según R. Schnackenburg, "hubiese encontrado aún mayor motivo de burla, dada su actitud malévola" ${ }^{88}$, porque los presentes habían retado a Jesús a salvarse a sí mismo (v. 30.32b), y Jesús, reconociendo su derrota, no hace otra cosa que invocar a Elías para que le salvara y por eso le dan de beber para prolongar la vida del condenado, esperando a que viniese Elías, sin embargo, Jesús muere casi inmediatamente, subrayándose así la ceguera y la incredulidad de los presentes 89 .

Por consiguiente, el alguien de entre ellos que ofrece de beber, tampoco viene explicado de quién se trata. $\mathrm{Al}$ respecto ha habido hasta tres propuestas de esclarecimiento; la primera, cree que sea un soldado romano que sabía quién era Elías; la segunda, piensa que los soldados habiendo sido reclutados de los alrededores, podían muy bien entender la lengua de los judíos; la tercera afirma que el soldado en cuestión era de proveniencia judía ${ }^{90}$. Lo único probable es que era un soldado, dado que los soldados eran los únicos que podían intervenir en favor de los condenados ${ }^{91}$. Ahora bien, de esas tres propuestas, asumiendo que se trate de un soldado romano que entra en el juego de la confusión proveniente de los judíos, este es quien ofrece vinagre al moribundo aparentemente como un gesto amable, pero tal gesto es inmediatamente negado por las palabras que acompañan al mismo, pues, tienen un carácter abiertamente burlesco. De otro lado, la figura del soldado en la narración sirve para unir a judíos y romanos en la no aceptación de Jesús como rey tanto con gestos como con palabras.

Entonces, lo que habría que entender en este episodio es, o bien que la finalidad de esta confusión es intencional en la narración marciana para resaltar el significado del grito, admitiendo que se trate de una oración de aban-

85. cf. R. SCHNACKENBURG, El Evangelio Según san Marcos, Vol. II, 323.

86. cf. R. PESCH, art. cit., 724 .

87. "In v. 29 these were Jews coming out of the city", cf. C.S. MANN, op. cit., 651.

88. op. cit., Vol. II., 323.

89: cf. J. GNILKA, op. cit., 892.

90. Ibid., 891; C.S. MANN.,op. cit., 652.

91. cf. F.M. URICCHIO - G.M. STANO, op. cit., 683. 
dono, o bien que Marcos quiera decir que sin saberlo "los presentes", no hacían otra cosa que cumplir con las Escrituras dándole de beber vinagre (cf. Sal 69, 22). Ambas interpretaciones se complementan, y lo que queda evidente es el sufrimiento del justo hasta el último momento de su agonía.

\section{TERCERA SUBSECUENCIA: Muerte y sepultura (v. 37-47)}

Compuesta de dos pasajes

\subsection{PRIMER PASAJE: Muerte (v. 37-41)}

Compuesto de tres fragmentos.

+ 37 Pero JESÚS emitiendo una gran voz, EXPIRÓ.

- 38 Y el velo del SANTUARIO fue rasgado en dos, de arriba hasta abajo.

+39 Viendo el centurión, que estaba presente frente a él, que así HABÍA EXPIRADO, dijo:

$::$ «VERDADERAMENTE ESTE HOMBRE ERA HIJO DE DIOS».

+ 40 Había también unas mujeres mirando desde lejos,

= entre las cuales, también María Magdalena,

= María la madre de Santiago el menor y de Joset, y Salomé,

$=41$ las cuales le seguían y le servían cuando estaba en Galilea,

$=y$ otras muchas que subieron con él a Jerusalen.

\subsubsection{COMPOSICIÓN}

a) Primer Fragmento: la reacción de Dios (v. 37-38)

Se compone de un segmento bimembre de seis términos, de tipo: a b c / a b c, el paralelismo es a nivel abstracto Jesús, el Hijo de Dios con el Santuario donde habita Dios. Emitiendo una gran voz, una acción de Jesús en paralelo con fue rasgado en dos. El expiró en paralelo con de arriba hasta abajo, es decir, el espíritu de Jesús que va de abajo hacia arriba y el velo del Santuario que es rasgado de arriba hasta abajo. Además, el hecho de que el velo del santuario fue rasgado, ha de ser tomado como una respuesta o reacción de Dios para confirmar a su Ungido. 


\section{b) Segundo Fragmento: la confesión del centurión (v. 39)}

Este fragmento es bimembre a seis términos, de tipo: (a b) C / (b' a') C. El paralelismo es también de tipo abstracto, en tanto Jesús es quien había expirado y en tanto que Jesús era el Hijo de Dios. Se relaciona con el fragmento precedente al repetirse el verbo expirar. Corresponde a la reacción del centurión.

\section{c) Tercer Fragmento: las mujeres (v. 40-41)}

Tiene dos segmentos. El primero es trimembre de tipo: $A A^{\prime} B$, unas mujeres con nombre propio: María Magdalena ${ }^{92}$, María la madre de Santiago el menor y de Joset, y Salomé ${ }^{93}$, estaban mirando desde lejos la muerte del crucificado (v. 40). El segundo y último segmento es bimembre de tipo: $a b / a^{\prime} b^{\prime}$, estas mujeres eran las que le seguían y le servían, cuando estaba en Galilea y ahora en Jerusalén. Se relacionan en tanto que los dos segmentos dan cuenta de la presencia de: unas mujeres, las cuales y otras muchas. Se diferencian debido a que en primer segmento indica que estaban presentes en el momento de la muerte de Jesús, mirando desde lejos, y el segundo informa que ellas ya seguían y servían a Jesús cuando estaba en Galilea y que subieron con él a Jerusalén.

Este pasaje se relaciona en sus fragmentos por el "ver" del centurión (v. 39a) y el "mirar" de las mujeres (v. 40a), también por el "expirar" de Jesús que viene mencionado dos veces. Tiene como segmento relevante la confesión del centurión. Se presentan dos tipos de testigos uno frente a él, el centurión (v. 39a) y las mujeres que miran desde lejos (v. 40a), sin poder decir ni hacer nada por el Maestro (cf. 13,1;14,14). Uno que empieza a creer y las otras ya creyentes, fieles hasta el último momento. Se diferencian unas de otras en tanto que el primer fragmento señala la reacción de Dios que rasgó el velo del

92. Magdala, es la Patria de María Magdalena. "Se ha identificado Magdala con Tariquea, en el Talmud Migdol Numayá, aldea de pescadores en al ribera occidental del mar de Galilea, cerca del actual el-meÿdel", cf. H. HAAG - A. van den BORN - S. de AUSEJO, "María Magdalena", DB, 1142 .

93. En cuanto a la identidad de estas tres mujeres que aquí aparecen con nombre propio, no se sabe mucho y entre los estudiosos no existe unanimidad a la hora de proponer una solución, cf. ibid., "María Magdalena", 1189-1190; ibid., "María, Madre de Santiago", 1188; de Salomé, es un nombre emparentado con Madre de Santiago el mayor y de Juan; ibid., "Salomé", 1775. Respecto a la segunda María, hay quienes como M. BARNouin, conjeturan que se tratataría de la madre del Señor, basándose en Mc 6,3: "¿no es éste el carpintero, el hijo de María, Joset, Judas y Simón?”, dice: 'Marie, mére de Jacques et de Jose' est une Marie autre mère de Jésus" cf. su artículo: "Marie, mère de Jacques et de José' (Marc 15.40)", NTS, 474. Pero, como Marcos no explica de quien se trata, es mejor dejarlo en la ambigüedad. 
Santuario, el segundo la reacción del centurión que consistió en una confesión de fe y el tercero describe el mirar silencioso de las mujeres, que seguían y servían a Jesús cuando estaba en Galilea y subieron con él a Jerusalén.

\subsubsection{CONTEXTO BÍBLICO}

La alusión a la rasgadura del velo del santuario (v. 38) evoca otra rasgadura, la de los cielos, cuando Jesús salía del agua después de haber sido bautizado (cf. 1,10) donde se usa el mismo verbo $\sigma \chi i \zeta \omega=$ rasgo (fueron rasgados), en pasivo como en el v. 38. Por otro lado, lo que sigue en 1, 10 es que el Espíritu, en forma de paloma, bajaba sobre él (Jesús); aquí cuando Jesús exhala el $\pi v \varepsilon v \hat{\mu} \alpha=$ espíritu (v. 37) -además de tener la misma raíz, éste es el senti-

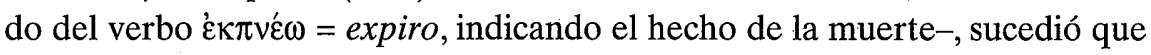
el velo del santuario fue rasgado. Velo que cubría el lugar (cf. Ex 26,31-37; Lv 16; Hb 6,19-20; 9,6-14; 1 R 6,16) donde el Sumo Sacerdote entraba solamente una vez al año ${ }^{94}$. Jesús irrumpe en el Santuario de una vez para siempre, no siendo necesarios más sacrificios.

La muerte repentina y violenta de Jesús acompañada de la gran voz, dado que la narración precedente relata los sufrimientos del condenado al suplicio de la cruz, recuerda sus propias palabras acerca de los tres anuncios de su Pasión (cf. 8,31; 9,30-32; 10,32-34); Jesús bebe la copa de la muerte (cf. Is 51,17; Jr 25,15.17.18; 49,12; Ex 23,31-34; Ha 2,16; Mc 10,38.39; 14,36); a su vez esta muerte es causa de rescate por muchos (cf. 10,45) y funda la Nueva Alianza (cf. 14,24), el Reino de Dios se hace presente ${ }^{95}$.

Cuando el centurión exclama su confesión: "verdaderamente este hombre era Hijo de Dios", por un lado, encuadra la muerte de Jesús como la de un justo (cf. Sal 22,9) que al final será glorificado; por otro lado, evoca el libro de la Sb 2,18: "Pues, si el justo es hijo de Dios, él le asistirá, y le librará de las manos de sus enemigos" (cf. también Sb 5,1-5); además confirma que Jesús es el ungido de Dios, es decir, rey. Igualmente este título recuerda las palabras con las que comienza la narración marciana, el llamado prólogo del Evangelio de Marcos: "Comienzo del Evangelio de Jesucristo, el Hijo de Dios" (1,1), las palabras que venían del cielo cuando Jesús fue bautizado: "Tú eres mi Hijo amado, en ti me complazco" $(1,11){ }^{96}$; las palabras de los espíritus inmundos: "Tú eres el Hijo de Dios" $(3,11)$; la del endemoniado de Gerasa: “¿qué tengo yo, Jesús, Hijo de Dios Altísimo?...” (5,7); y la voz desde las nubes en la transfiguración: "Éste es mi Hijo amado, escuchadle" $(9,7)$.

94. cf. V. TAYLOR, op. cit., 596.

95. cf. B. ESCAFFRE, art. cit., EstBib, 337.

96. cf. F.J. MATERA, "The prologue as the interpretative key to Mark's Gospel”, JSNT, 14-15. 


\subsubsection{INTERPRETACIÓN}

“Pero Jesús emitiendo una gran voz, expiró", al parecer Marcos relata solamente un grito (v. 34) ${ }^{97}$. Sin embargo, hay razones suficientes para que se reconozca un segundo grito inarticulado, está el hecho que previamente a este segundo grito se ha narrado la escena del malentendido de las palabras del moribundo, el ofrecimiento del vinagre y la manera como empieza el v. 37 con un "pero" adversativo, entonces este segundo $\phi \omega v \varepsilon ́ v \mu \varepsilon \gamma \alpha \lambda \eta \dot{v}=u n a$ gran voz, hay que entenderlo bien como un grito de triunfo, o simplemente como un grito que anuncia al mundo la muerte de Jesús 98 , el justo sufriente. De este modo, este grito se suma a los signos que acompañaron a la muerte de Jesús (cf. Mc 15,37.38.39) ${ }^{99}$.

Dada la extrema debilidad del crucificado, un grito semejante señala una muerte extraordinaria, ya que, normalmente los padecimientos de los condenados se prolongaban por horas y a veces por días ${ }^{100}$, una muerte así repentina y rápida puede significar un signo de superación y de victoria. De hecho tal como viene presentada esta muerte tiene alcances enigmáticos, primero porque se trata de un grito inarticulado (v. 37), en lo que coincide con Mt 27,50, cosa que no sucede en Lc 23, 46 cuando narra el expirar de Jesús, además de que solamente narra un grito, tampoco en Jn 19,28.30 que no habla precisamente de gritos, sino de dichos solemnes: "Tengo sed" y "Todo está cumplido".

Las escenas descritas son distintas de evangelista a evangelista 101. Marcos relata la siguiente sucesión de hechos: mención de la hora sexta, las

97. En Mt 27, 45-50 se relata específicamente dos gritos cf. J. RADERMAKERs, op. cit., 315; J. MATEOS - F. CAMACHO, op. cit., 389; J. GNILKA, op. cit., 892; S. LÉGASSE, El proceso..., 11-113.

98. Contra L. CAZA que interpreta las dos menciones de la única gran voz de Jesús como una precisión de la manera como Jesús murió, cf. su art. cit., 174; en favor de los dos gritos de Jesús, cf. J. GNILKA, op. cit., 892.

99. Según J. PILCH la muerte de Jesús con los hechos que le preceden es una muerte honorable, por eso provoca la admiración del centurión, que ve en esta muerte el fallecimiento de una persona inocente, cf. su artículo: "Death whit Honor: The Mediterranean Style Death of Jesus in Mark", $B T B, 70$.

100. cf. R. SCHNACKENBURG, op. cit., 324; R. PESCH, art. cit., 727; V.TAYLOR, op. cit. 596; W.L. LANE, op. cit., 574.

101. En Mateo 27, 45-50, con ligeras variantes sigue igual hasta cuando alude a algunos de los presentes, de los cuales uno de ellos ofrece de beber (esponja-vinagre-caña), son los algunos quienes dicen las palabras que en Marcos es puesta en boca del alguien, a lo que sigue el segundo grito y "exhaló el espíritu". En Lucas 23, 44-46, la indicación de las horas permanece invariable, en cambio la oscuridad se debe a un eclipse solar y el rasgarse del velo del Santuario antecede al único grito: "Padre en tus manos pongo mi espíritu", concluyendo con " $y$ dicho esto expiró". No menciona el ofrecimiento de la bebida, tampoco a los presentes, ni al alguien. Juan $(19,28-30)$ difiere casi totalmente con los sinópticos, no menciona las horas, ni las tinieblas, en cambio introduce: "para que se cumpliera la Escritura", dice: "tengo sed", puntualiza que había allí una vasija llena de vinagre, que a Jesús le alcanzan de beber con una rama de hisopo, quien habiendo tomado el vinagre, dijo: "todo está cumplido" e "inclinando la cabeza entregó el Espíritu". 
tinieblas desde la hora sexta hasta la hora nona en la que Jesús lanza su primer grito, continua con el algunos de los presentes que comentan que llama a Elías, alguien indeterminado, posiblemente un soldado que empapando una esponja en vinagre sujetado a una caña ofrece de beber al moribundo que no se sabe si la bebe o no, al tiempo que pronuncia unas palabras no necesariamente misericordiosas ni respetuosas (v. 36) y el segundo grito seguido del expirar de Jesús.

En todo caso esta muerte, que no viene expresada en ninguno de los cuatro evangelios con el verbo $\alpha \pi 0 \theta v \eta n \sigma \kappa \omega=$ muero o un sinónimo, en su singularidad es una muerte salvífica (cf. 10,$45 ; 14,24$ ) y señala la venida del Reino de Dios; una vez que se han marchado las tinieblas, esta muerte trae la luz del Reino.

"EI velo del Santuario fue rasgado en dos de arriba hasta abajo", es otro signo enigmático que acompaña a la muerte de Jesús y que puede ser interpretado al menos de dos maneras ${ }^{102}$. Primero significando que con la muerte de Jesús el Santuario y el culto que se desarrollaba hasta entonces allí, pierden importancia, por tanto, el velo del Santuario que cumplía la función de cubrir el lugar del Santo de los Santos, donde se desarrollaba el sacrificio por los pecados cada año (cf. Lv 16; 1 R 8,6; Hb 9,6-14), llega a su fin al ser rasgado de arriba hasta abajo, es decir, viene destruido. Sería, asimismo, una respuesta a las falsas acusaciones de $15,29 \mathrm{~b} ; 14,58$ y al cumplimiento de lo que Jesús había anunciado en 13,2 "no quedará piedra sobre piedra que no sea derruida" aunque en este caso las palabras y el contexto son distintos.

La segunda interpretación, parte del hecho de que el velo cumplía la función de esconder la revelación del Señor y el de impedir la visión de la grandeza de Dios: "el velo os servirá para separar el Santo del Santo de los Santos", también era llamado: "el velo que lo cubre" (Ex 35,12; Nm 4,5) e igualmente cubría el Arca del Testimonio (Ex 30,6; 40,3), es decir, tenía un significado cultual. Ahora que ha sido rasgado puede ser interpretado como apertura del acceso a Dios para los no sacerdotes y para los paganos o también como la revelación de la majestad de Dios.

Esta dos interpretaciones en vez de oponerse se complementan. Es más, la presencia del aoristo pasivo (fue rasgado) puede ser tomado como un pasivo divino, significando que detrás de este hecho hay una directa intervención de Dios, en el sentido de que Dios abre una posibilidad de alcanzarlo, de verlo, de darlo a conocer a todos como el salvador, incluidos los paganos, y no como alguien que permanece cubierto, escondido y lejano, lo que viene insinuado por la confesión del centurión, tras haber visto que Jesús había expira-

102. cf. J. GNILKA, op. cit., 893. 
do. Y esto a través de la muerte de su Hijo ${ }^{103}$ en la cruz que comienza a tener sus dos primeros efectos.

"Verdaderamente este hombre era Hijo de Dios", mientras los adversarios de Jesús (transeúntes, sumos sacerdotes y escribas, el alguien), juntamente con sus propios compañeros de suplicio (vv. 29-32) permanecen incrédulos, la fe emerge en uno de los que hasta hacía poco era también enemigo del crucificado, del que menos se podía esperar surge una tal actitud, del centurión, un pagano. Una vez más, un extraño, se solidariza con aquel que había sido abandonado por sus discípulos, por su pueblo y por aquellos que debían haberlo reconocido como Mesías, como rey $(14,47-49.62)$. Este rey ahora no sólo tiene un servidor real (v.21), sino también un soldado de su parte. Igualmente, esta confesión es la cumbre del evangelio marciano, pues, inició dando a Jesús este título (cf. 1,1), después Pedro, discípulo y judío confesó que era el Cristo (cf. 8, 29), ahora un pagano confiesa que Jesús es el Hijo de Dios, es decir, el lector ahora puede entender por qué Jesús es el Cristo, el Ungido y el Hijo de Dios.

“Unas mujeres mirando desde lejos", la proclamación de la Buena Nueva de Dios, tal como lo presenta Marcos, Jesús la inició en Galilea $(1,14)$ y a primera vista ahora acaba de concluir en Jerusalén: subieron con él a Jerusalén unas mujeres que aparecen justamente en estos dos versículos (4041). En el Evangelio marciano antes no se dice nada acerca de ellas, sin embargo aquí se dice que ya estaban presentes "cuando estaba en Galilea, donde le seguían y le servían". Como el centurión estaban mirando con la diferencia de que lo hacían desde lejos. Sin duda son discípulas de Jesús (pues, le seguían, el seguir en Marcos es un verbo que sirve para significar el discipulado) que se convierten en testigos (mirando desde lejos) de la muerte de Jesús y de todo lo que ha sido narrado en la primera y segunda sotosecuencia, juntamente con otras muchas (v. 41b). Con esto se aumenta un signo más, es decir, en ausencia de los discípulos (cf. 14, 50-52), son las mujeres las únicas que permanecen fieles al Maestro. Están en número de tres como en la transfiguración tres son los discípulos, aquí las discípulas son tres como si se quisiera significar la verificación de aquellas que han comprendido que el seguimiento de Jesús comporta el seguimiento de la cruz ${ }^{104}$. Es aquí donde conclu-

103. Según la Biblia TOB, en la nota " $\mathrm{z}$ ", los vv. 38 y 38 "entienden subrayar la importancia de la muerte de Jesús para la historia de la salvación. El velo que cerraba el Santo de los Santos (cf. Ex 26,33) o el edificio del templo (cf. Ex 26, 36-37) se rasga; símbolo de libre acceso a Dios (cf. Heb 6,19-20; 9,3.6-12) o el presagio del final del Templo. Mc tiene cuidado de todo lo que anuncia la participación de los paganos en la salvación", cf. TOB, 2309.

104. cf. J. GNILKA, op. cit., 896. 
ye la narración de la crucifixión, con unas discípulas que son consecuentes hasta el final con el Maestro.

\subsection{SEGUNDO PASAJE: "Un sepulcro excavado en roca"(v. 42-47)}

Compuesto por tres fragmentos.

:: 42 Y ya la tarde llegada,

$::$ es decir,

$=43$ viniendo José de Arimatea,

$:$ que también

= teniendo valor entró donde Pilato como era la Preparación,

el antesábado,

miembro respetable del Consejo, él estaba esperando el REINO DE DIOS, y pidió el cuerpo de JESÚS.

+ 44 Pilato se maravilló

de que ya estuviese muerto,

+ y haciendo llamar al centurión,

+ 45 Informado por el centurión,

le preguntó si hacía tiempo (que) murió.

concedió el cadáver a José,

= ${ }^{46}$ y comprando una sábana,

descolgándole (lo) envolvió en la sábana

= y lo puso en un sepulcro

= e hizo rodar una piedra

que estaba excavado en roca;

sobre la puerta del sepulcro.

+ 47 María la Magdalena y María la de Joset: observaban dónde era puesto.

\subsubsection{COMPOSICIÓN}

\section{a) Primer Fragmento: José de Arimatea (v. 42-43)}

Se compone de dos segmentos, el primero es bimembre, de tipo paralelo: a b / a' b'; el segundo es trimembre de tipo: $A B A^{\prime}$. Se relacionan de manera que el primer segmento señala el final del día: ya la tarde llegada, es la introducción de lo que se dirá a continuación, marca el cambio de las acciones hasta este momento narradas e informa que el día de la crucifixión era un

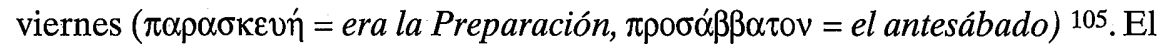
segundo segmento que es trimembre, de tipo: $A B B^{\prime}$, introduce un nuevo personaje, un judío notable José de Arimatea que estaba esperando el Reino de

105. La Preparación o el antesábado se refiere al día viernes en el que los judíos hacen los preparativos para celebrar el sábado, que es un día de reposo y de oración en familia; cf. E.

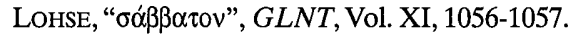


Dios, con un arranque de valor pide a Pilato el cuerpo de Jesús. Se diferencian porque el primer segmento indica el tiempo, el segundo describe la petición del cuerpo de Jesús por parte de José de Arimatea.

\section{b) Segundo Fragmento: la sepultura de Jesús (v. 44-46)}

Compuesto de dos segmentos, el primero es trimembre, de tipo: $\mathrm{ABC}$. El sujeto principal es Pilato que se maravilla de la temprana muerte de Jesús, hace llamar y pregunta al centurión acerca de la muerte de Jesús, una vez informado por el centurión, concede el cadáver a José. A su vez este segmento es el centro del resto del pasaje en razón de que testimonia la certeza de la muerte de Jesús que ahora va a ser sepultado. El segundo segmento es igualmente trimembre, de tipo: A B C. El sujeto principal es José de Arimatea que compra, descuelga, envuelve, pone y hace rodar. Estos dos segmentos se relacionan debido a que el primero da cuenta de la muerte de Jesús y el segundo atestigua la sepultura de Jesús. Se diferencian en el hecho de que los personajes principales, es decir, los sujetos representan a los romanos y a los judíos como los responsables directos de todo lo que sucedió a Jesús desde de su captura, proceso, condena, ejecución y sepultura. Otra diferencia es que la actuación de Pilato es la de una autoridad que se limita a cumplir con su papel a nivel político, sin nada que indique un aspecto religioso, aunque sí con un gesto de benevolencia toda vez que los romanos no se preocupaban de la sepultura de los ajusticiados, menos de un rebelde político ${ }^{106}$; en cambio José de Arimatea es un creyente (estaba esperando el Reino de Dios) que se preocupa de que la memoria del que es sepultado ( $\mu \nu \eta \mu \varepsilon^{\prime} \omega=$ memoria, sepulcro $\mathrm{v}$. $46 \mathrm{bc}$ ), no quede borrada y hace que se recupere la dignidad del que murió contado entre los malhechores $(15,27-28)$. Hay que subrayar también que entre estos dos segmentos hay un brusco cambio del sujeto, sin ninguna anticipación, se pasa de las acciones de Pilato (vv. 44-45) a las acciones de José de Arimatea (v. 46).

\section{c) Tercer Fragmento: las mujeres (v. 47)}

Compuesto de un segmento unimembre de dos términos, que evoca la presencia de las mujeres de los vv. 40-41 como testigos oculares, primero de la muerte de Jesús, ahora de su sepultura y cierra la secuencia con un verbo que indica que son testigos irrefutables: observaban, es decir, no solamente ven, sino que se cercioran de los detalles. 


\subsubsection{CONTEXTO BÍBLICO}

La anotación de "ya llegada la tarde" (v. 42a) rememora la misma expresión que Marcos usa cuando narra la llegada de Jesús con los doce al lugar donde iban a celebrar la Pascua, que se convertirá en la institución de la eucaristía (cf. 14,22-

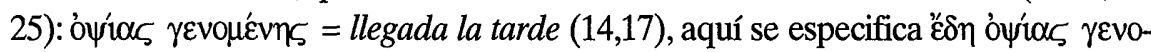
$\mu{ }^{\prime}{ }^{\prime} \eta_{S}=$ y a llegada la tarde. En el primer caso recuerda como en Ex 12,6 que el cordero debía ser inmolado al atardecer, que según la versión de los LXX lo expresa con un sinónimo $\pi \rho o_{\zeta}$ É $\sigma \pi_{\varepsilon} \rho_{\alpha} \alpha \nu=$ hacia el atardecer, aquí el contexto es sin duda igualmente el de la inmolación del cuerpo de Jesús que en seguida va a ser descolgado de la cruz después de que se compruebe su muerte. El cuerpo y la sangre de Jesús que ha sido inmolado por muchos (cf. 14,24) ${ }^{107}$, hace que esta muerte esté en paralelo con la eucaristía. Por otro lado, Marcos precisa que era la Parasceve o la Preparación, es decir, el antesábado (cf. Lc 23,54; Jn 19,31.34: los cuerpos no debían quedar en sábado en la cruz), y el sábado es para los judíos un día de reposo que comienza con el ocultarse del sol del día viernes, añadiendo a esto que aquel año el sábado coincidía probablemente con el primer día de la fiesta de los ázimos 108 .

La nominación de José de Arimatea que cumple con un gesto genuinamente judío, recuerda Dt 21,22-23:

"Si un hombre reo de delito de muerte, ha sido ejecutado y le has colgado de un árbol, no dejarás que su cadáver pase la noche en el árbol; lo enterrarás en el mismo día porque un colgado es una maldición de Dios. Así no harás impuro el suelo que el Señor tu Dios te da en herencia" ${ }^{109}$.

107. En Mateo la alusión a la eucaristía es más evidente como si se estuviese cumpliendo la invitación que Jesús hiciera en 26,26: tomad, comed esto es mi cuerpo y en 27, 59 José de Arimatea toma el cuerpo de Jesús. Para Juan que alude a que al cordero pascual no debía rompérsele ningún hueso $(19,31.36)$, se preocupa en señalar el paralelo con la fiesta de la Pascua, lo que para Marcos y el resto de los dos sinópticos resulta más importante recalcar la realidad del sábado (cf. 14, 42; Mt 27, 56; Lc 23, 54), cf. J. RADERMAKERS, op. cit., 316. Arimatea, "probablemente va identificada con Rentis, en el pasado Ramatajim, la patria de Samuel (1 S 1,1) situada en la parte septentrional de la Judea", cf. J. GNILKA, op. cit., 906; también S. LÉGASSE, La historia, 156.

108. cf. F.M. URICCHIO - G.M. STANO, op. cit., 643.

109. Mateo $(27,57)$ y Juan $(19,38)$ explican que José era "discípulo de Jesús", mientras Marcos 15,43 y Lc 23, 51 observan que José "estaba esperando el reino de Dios" y que era miembro del sanedrín. Aunque Lucas $(23,51)$ acentúa que él no había consentido con el decreto y las acciones de ellos (es decir, los miembros del Sanedrín). José de Arimatea con su gesto de pedir el cuerpo de Jesús "no considera a Jesús como un malhechor", comporta un riesgo, en la medida en que Pilato era un hombre caprichoso y en tanto que el pueblo había pedido la crucifixión de Jesús o también en el hecho que la intervención de José podía despertar la sospecha de que fuese un cómplice del ajusticiado, además pone en juego su posición de miembro respetable del Consejo, cf. J. GNILKA, op. cit., 906. Arimatea, "probablemente va identificada con Rentis, en el pasado Ramatajim, la patria de Samuel $(1$ S 1,1) situada en la parte septentrional de la Judea", cf. J. GNILKA, op. cit., 906; también S. LÉGASSE, La historia, 156. 
De otro lado, el valiente comportamiento de José de Arimatea $(15,43 \mathrm{c})$ en pedir el cuerpo de Jesús a Pilato, pone èn paralelo la acción de los valientes de entre los habitantes de Yabéš de Galaad que caminando de noche van a rescatar el cuerpo del rey Saúl que los filisteos habían colgado en los muros de Bet San, para darle una digna sepultura (cf. 1S 31,10-13). Saúl es el ungido del Señor, también Jesús. Es más, según J. Radermakers: "sólo una personalidad importante podía pedir a Pilato el cuerpo de un condenado, inmediatamente después de la muerte" 110 , en ausencia de sus familiares como ocurre en Marcos.

La sábana con que es envuelto (15,46a) el cuerpo de Jesús, parece evocar la sábana con que iba cubierto el joven que seguía a Jesús después de haber sido arrestado por los siervos de los sumos sacerdotes, de los escribas y de los ancianos $(14,43)$, pero que habiendo sido detenido escapó desnudo. El discípulo que escapa y abandona a Jesús queda desnudo, sin honor, sin dignidad, expuesto a la vergüenza pública (cf. Ez 23,29; Is 47,1-4) 111, el Maestro que había sido desnudado (cf. 15,24) ahora es envuelto, recobra su dignidad, "entre los judios era un deshonor ser sepultado desnudo" 112.

El retorno de las mujeres (vv. 40-41), aunque en número disminuido, no se vuelve a nombrar a Salomé ni a las otras muchas. Como ya se ha señalado, se constituyen una vez más en testigos excepcionales (v. 47), esta vez del lugar donde Jesús fue sepultado.

\subsubsection{INTERPRETACIÓN}

"Viniendo José de Arimatea", aparece un nuevo discípulo de Jesús 113, primero fue Simón de Cirene, de entre los judíos comunes y corrientes, uno de los de a pie, sin mayor importancia en la religión judía que su adhesión a la misma, quien ayudó a Jesús que no podía cargar con su cruz $(15,21)$ dada su avanzada debilidad a causa de la flagelación que sufriera $(14,15)$, después surgió el Centurión que inesperadamente confiesa su fe en el Hijo de Dios al haber visto la manera como había expirado $(15,37)$, convirtiéndose en el primer discípulo de entre los paganos, de entre los romanos y, en este pasaje surge este nuevo discípulo de entre los judíos,

110. cf. J. RADERMAKERS, op. cit., 316-317; R. SCHNACKENBURG, 331.

111. cf. X. LeON-Dufour, "Vergogna e nudità", DTB, 1355; Ibid. "Veste", DTB, 1366.

112. cf. J. GNILKA, op. cit., 909.

113. Contra J. MATEOS - F. CAMACHO, op. cit., 392 y J. GNILKA, op. cit., 906, es verdad que

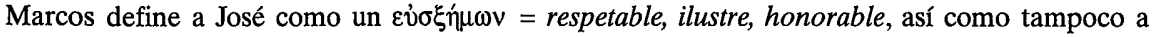
Simón de Cirene $(15,21)$ definió como discípulo, menos al centurión, pero por la acción del primero, la confesión del segundo y el gesto del tercero los tres pasan a ser discípulos de Jesús (cf. 9, 40: "el que no está contra nosotros, está por nosotros"). Es más algunos piensan como J.D. Crossan, que José de Arimatea, no existió y que como personaje es pura invención literaria de Marcos: "consumate theological fictions" cf. el artículo de G. O'Colurns - D. Kendall, "Did Joseph of Arimatea Exist", Bib, 239. 
un judío importante, perteneciente al Sanedrín ${ }^{114}$, es decir, al grupo de las autoridades religiosas que mandaron crucificar a Jesús. Al pedir el cuerpo de Jesús para sepultarlo, suple la ausencia de los discípulos que abandonaron al Maestro $(14,50)$ 115. José de Arimatea como los anteriormente mencionados no es mencionado en el resto del Evangelio marciano, cumple con la sepultura de Jesús y vuelve a desaparecer, pero lo que resta claro es que también él estaba esperando el Reino de Dios (v. 43b), es decir, reconoce en Jesús al Mesías ${ }^{116}$. No unge a Jesús antes de ponerlo en el sepulcro como corresponde a la tradición judía, como si estuviese enterado de que ya fue ungido (cf. 14,8). Este nuevo discípulo se suma igualmente a aquellas mujeres fieles que seguían y servían al Maestro desde cuando estaba en Galilea y que subieron con él a Jerusalén (v. 41).

"Estaba esperando el Reino de Dios", por encima de todas las contradicciones y el rechazo general de los que mandaron crucificar a Jesús como un impostor, el Reino de Dios irrumpe en la historia de la humanidad, aun cuando los hombres quieran detenerlo y no reconocerlo, empezando por los sumos sacerdotes, los escribas y los ancianos, el poder político de turno encarnado en la autoridad romana con Pilato a la cabeza, hasta los mismos discípulos que se han marchado temerosos de perder la vida.

Jesús ha muerto verdaderamente y su muerte es una muerte salvífica $(14,24)$. Se instala una Nueva Pascua, rompiendo los viejos esquemas, tanto que José de

114. Era "la suprema autoridad administrativa del pueblo judio [...], se remonta al período helenístico (fines del siglo II a. C.)", cf. H. HAAG - A. van den BORN - S. de AUSEJO, "Sanedrín", DB, 1791-1792.

115. Normalmente un ajusticiado debía ser sepultado por sus parientes, cf. S. LÉGASSE, $L a$ historia, 158. Pero, también, cualquiera podía pedir el cadáver de los ajusticiados cf. F.M. URICCHIO - G.M. STANO, op. cit., 643.

116. El uso que hace Marcos del kói con valor adverbial "también" y no del simple copulativo " $y$ ", hace que la interpretación entre los exégetas no sea unánime; por un lado, se afirma que José todavía estaba esperando el Reino de Dios concebida al modo judaico, por tanto, no era discípulo cf. V. TAYLOR, op. cit., 600; J. GNILKA, op. cit.,906; J. MATEOS - F. CAMACHO, op. cit.,392; C.S. MANN, op. cit., 657; que habría tomado la iniciativa de pedir el cuerpo de Jesús a Pilato para sepultarlo, por el simple sentimiento de un judío piadoso que quería cumplir y ser fiel con la Ley (Dt 21,23), cf. S. LÉGASSE, La historia, 158. Por otro lado, hay quienes opinan que el Reino de Dios, del cual hablaba Jesús (Mc 1, 15; 4,11.26.30; 9,1.47; 10,14.15.23.24.25.34;14,25;15,43), era el que José esperaba, cf. M. GALIZZI, op. cit., 301; F.M. URICCHIO - G.M. STANO, op. cit., 644; J. RADERMAKERS, op. cit., 317. Parece ser más razonable la segunda posición, debido a que el también hay que ponerlo en relación a las mujeres que vienen mencionadas en los vv. 40-41 como las que permanecieron fieles a Jesús aún en el fatal momento de su crucifixión, Marcos no explica que el Reino de Dios que José esperaba era el concebido al modo judaico, al contrario siempre que ha mencionado el Reino de Dios en boca de Jesús se refería al que precisamente Jesús comenzó a anunciar en 1,15 y lo siguió haciendo hasta cuando instituyó la Eucaristía (cf. 14,25). Y la única vez que lo hace para referirse a José de Arimatea que estaba esperando el Reino de Dios, sería contradictorio que lo hiciera para hablar del Reino de Dios concebido al modo judaico y que sería un simple simpatizante, en vez de discípulo, cuando todo el Evangelio marciano se preocupa en señalar en que consiste el discipulado. Como igualmente sería ilógico inferir que Marcos cuando narra la confesión del centurión estaría queriendo significar con el "verdaderamente este hombre era Hijo de Dios" que el centurión estaría pensando en el hijo de alguno de los dioses romanos. 
Arimatea, un judío piadoso a todas luces "entró donde Pilato", con el suficiente coraje de entrar en la casa de un pagano, sin importarle la tradicional impureza en la que caía un Judío que entraba en la casa de un pagano, arriesgando todo incluso su posición en el pueblo judío como miembro del Sanedrín; antes, el velo del Santuario fue rasgado por Dios, ahora el hombre responde a lo que Dios revela detrás de estos hechos desagradables y del que Dios se sirve para darse a conocer. La conversión y la espera; el Reino de Dios comporta un cambio radical respecto al pasado del que acepta a Jesús como el Mesías. Por eso, José de Arimatea como Simón de Cirene, sale del anonimato y pasa a ser reconocido como creyente.

Otra cosa a resaltar es que este Reino de Dios que empieza a establecerse con la muerte del Maestro, después del trabajo de proclamación que hiciera Jesús y que termina justamente un viernes, el Hijo de Dios entra en el descanso de la muerte, en el šabbãt, en la cesación del trabajo (Gn 2,2-3; Ex 20,8-11; 34,21, etc.) como lo hizo Dios, el Padre del Hijo de Dios (Mc 1,1.11;9,7), después de haber llevado a término su trabajo de creación. Como la creación significó un nuevo orden en la tierra que era caos y confusión (Gn 1,2) una vez que Dios terminó su obra, cesó de toda obra creadora, bendijo el día séptimo, y este día séptimo se convertirá en señal de la Alianza (cf. Ex 31,12-17), así también el cesar del obrar y de la vida de Jesús, funda un nuevo orden de cosas, una Nueva Alianza (Mc 14,24), no solamente los judíos pueden acceder a Dios, sino también los paganos (empezando con el centurión, v. 39), el Reino como la semilla de la parábola (cf. Mc 4,26-29) brota y crece sin que se sepa cómo, da fruto por sí misma, "hasta llegar al término previsto por Dios" 117.

“Concedió el cadáver a José", el cuidadoso uso que Marcos hace de los tér-

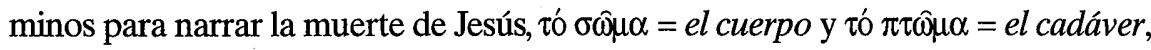
sirve para subrayar la muerte real y no aparente del Maestro. Lo que José de Arimatea recibe es un cadáver, un cuerpo que ya no tiene vida, tanto que Pilato para cerciorarse de la muerte del crucificado llama al centurión para preguntarle si hacía tiempo que murió. Llama igualmente la atención que sólo en boca de

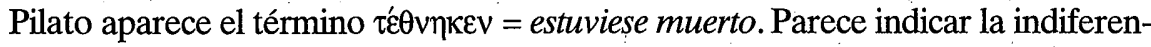
cia de un pagano delante de la muerte de Jesús. Antes, Marcos había usado un término cargado de teología ' $\xi_{\xi}^{\prime} \varepsilon ́ \pi v \varepsilon v \sigma \varepsilon v=$ expiró, para significar la misma realidad en términos de dejar escapar el espíritu que lo había recibido en el bautismo.

"Lo puso en un sepulcro", no puede ser más digno el final de la vida del Maestro 118 . Se le envuelve en una sábana y se asegura el sepulcro con una piedra (v. 46ac); el que ha sido contado entre los malhechores, no viene sepul-

117. cf. Biblia de JeRUSALÉn, 55.

118. Aunque R.E. Brown, piensa lo contrario, diciendo que en Marcos faltan elementos como la unción y el lavado del cadáver del que va a ser sepultado, como para que se pueda decir que se trató de una sepultura honorable, el que solamente lo haya envuelto en una sábana, hace de la sepultura de Jesús escasamente honorable, cf. en su artículo: "The Burial of Jesus (Mark 15: 42-47)", CBQ, 243. 
tado entre ellos (cf. Is 53, 9: "y se puso su sepultura entre los malhechores"), es colocado en un sepulcro ya previamente excavado en roca, probablemente perteneciente a la familia de José. De estos hechos son testigos 119 las dos mujeres (cf. Dt 19,15) que observaban la sepultura y el lugar donde era puesto Jesús, aunque no toman parte en la sepultura.

Por todas las acciones de José de Arimatea debe ser contado como un discípulo más de Jesús, igualmente hay que ponerlo en paralelo a la confesión del centurión: "Verdaderamente este hombre era Hijo de Dios", es decir, el Mesías comienza a ser reconocido como tal, tanto en el mundo pagano como en el mundo Judío. Desde luego la comunidad de los discípulos queda incluida en este reconocimiento, por la presencia de las mujeres.

\subsection{EL CONJUNTO LA SUBSECUENCIA}

37 Pero JESÚS emitiendo una gran voz, expiró. 38 Y el velo del SANTUARIO fue rasgado en dos, de arriba hasta abajo.

39 Viendo el centurión, que estaba presente frente a él, que así había expirado, dijo: «VERDADERAMENTE ESTE HOMBRE ERA HIJO DE DIOS».

40 Había también unas mujeres mirando desde lejos, entre las cuales, también María Magdalena, María la madre de Santiago el menor y de Joset, y Salomé, 41 las cuales le seguían y le servían cuando estaba en Galilea, y otras muchas que subieron con él a Jerusalén.

42 Y ya la tarde llegada, como era la Preparación, es decir, el antesábado, 43 viniendo José de Arimatea, miembro respetable del Consejo, que también él estaba esperando el REINO DE DIOS, teniendo valor entró donde Pilato y pidió el cuerpo de JESÚS.

44 Pilato se maravilló de que ya estuviese muerto, y haciendo llamar al centurión, le preguntó si hacía tiempo (que) murió. 45 Informado por el centurión, concedió el cadáver a José, 46 y comprando una sábana, descolgándole (lo) envolvió en la sábana y lo puso en un sepulcro que estaba excavado en roca; e hizo rodar una piedra sobre la puerta del sepulcro.

47 María la Magdalena y María la de Joset. observaban dónde era puesto. 


\subsubsection{COMPOSICIÓN}

Esta subsecuencia está compuesta de dos pasajes y cada uno de tres fragmentos. El primer pasaje se divide así: a) vv. 37-38; b) 39; c) vv. 40-41; el segundo pasaje: a) vv. 42-43; b) vv. 44-46; c) 47. Cada pasaje en el primer fragmento menciona a Jesús, en el primer pasaje como término inicial (v. 37) y el segundo pasaje como término final (v. 42). El segundo fragmento del primer pasaje, señala como testigo al centurión (v. 39) un romano; en el tercer fragmento las mujeres-discípulas, cumplen igualmente, la función de testigos en grupo de tres: María Magdalena, María la Madre de Santiago el menor y de Joset y Salomé (v. 40bc), todas judías. En el segundo pasaje, el segundo fragmento alude también como testigo al centurión (vv. 44-45); en el tercer fragmento las mujeres son una vez más testigos: María Magdalena y María la de Joset (v. 47), pero esta vez desaparece Salomé. De igual forma cada pasaje menciona en dos ocasiones el deceso de Jesús, en el primer pasaje con los verbos: expiró (v. 37) y había expirado (v. 39), en el segundo pasaje con: estuviese muerto (v. 44a) y murió (v. 44b).

Los dos pasajes se relacionan al narrar la muerte de Jesús y su consiguiente sepultura, se atestigua cuatro veces la muerte (vv. 37.39.44ab) y dos veces la sepultura (v. 46bc). Igualmente cada pasaje tiene en el primer fragmento una referencia a Dios, en el primer pasaje: "verdaderamente este hombre era Hijo de Dios" (v. 39b), en el segundo pasaje: "el Reino de Dios".(v. 43b); aunque en el primer fragmento hay otras dos referencias: Jesús, Santuario (vv. 37.38) y en el segundo vuelve el nombre de Jesús (v. 43c). Otro elemento que los relaciona es el ver del centurión (v. 39), el mirar y el observar de las mujeres (v. 40.47). La presencia de las mujeres en ambos pasajes es fundamental para aseverar la certeza de la muerte y la sepultura de Jesús, incluida la crucifixión y de todos los hechos en torno a la pasión.

Se diferencian, porque en el primer pasaje se narra el momento mismo de la muerte de Jesús y en el segundo pasaje se habla acerca de la muerte de Jesús y se procede a su sepultura.

\subsubsection{INTERPRETACIÓN}

EI Reino de Dios se establece para toda la humanidad. El centurión que representa a los paganos de toda la tierra, reconoce en Jesús al Hijo de Dios, es decir, al ungido del Señor, al rey quien es a la vez el Hijo de Dios (2 S 7,14); los judíos incrédulos empiezan a convertirse en la persona de José de Arimatea, quien como todo judío esperaba que el Mesías estableciera el Reino de Dios, al ser presentado en esta subsecuencia como el que da sepultura a Jesús 
le otorga un honor de rey ${ }^{120}$, por tanto, también de ungido de Dios, es decir, de Mesías, como hicieron los valientes de Yabéš con el rey Saúl (1 S 31,13); los discípulos representados por las mujeres que observaban de lejos, aun cuando todos los discípulos varones huyeron, ha quedado este resto fiel de las mujeres, que X. Pikaza las llama "reserva mesiánica de Jesús" 121 y en este sentido son las verdaderas discípulas, consecuentes hasta al final con el Maestro, las que han creído en su palabra. Son igualmente las únicas personas que pueden dar testimonio de lo que han visto, de su muerte que ha estado rodeada de signos divinos. Por eso, es una muerte redentora.

La presencia de estas personas en un momento tan decisivo de la vida de Jesús, habla por sí sola, pues ellas están unidas por una misma fe en el crucificado. El Reino de Dios ha comenzado y en él tiene cabida todo aquel que cree que Jesús es el Hijo de Dios (Mc 1,1). Y todo creyente tiene el deber de testimoniar y hacer presente en medio de los hombres este nuevo Reino, que de entre las tinieblas de la muerte (cf. Mc 8,31-33; 9,30-32; 10,32-34) surge para irradiar vida (cf. Mc 16,6: "no os asustéis. Buscáis a Jesús de Nazaret, el Crucificado; ha resucitado, no está aquî"). La muerte no vence. Es solamente un paso, es decir, una Pascua. Por eso hay que anunciarla, comunicarla como Evangelio, como Buena Noticia, para despertar la misma fe de los testigos de esta ignominiosa muerte, que irónicamente engendra vida.

120. La historia de este primer rey de Israel como la de Jesús está llena de contrastes, salvando las diferencias, la historia de Saúl es "una historia compleja, contradictoria, rica de aristas. Una historia que encuentra, en el drama de su fin, una dimensión de trágica grandeza. Y los honores que los ciudadanos de Yabéś tributan a su soberano dan alivio también al lector, que participa al horror de aquella muerte y quisiera también él, exteriorizar la propia piedad y donar un último gesto de amor a aquel hombre así misteriosamente señalado de tanto dolor" cf. B. COSTACURTA, Con la cetra e con la fionda. L'ascesa di Davide verso il trono, 223.

121. cf. X. PikAZA, op. cit., 418. 


\section{EL CONJUNTO DE LA SECUENCIA}

21 Y obligan a uno que pasaba, a Simón de Grene, que volvía del campo, el padre de Alejandro y de Rufo, para que llevara su auz. 22 Y le conducen al lugar del Gólgota, -que significa-: lugar del Cráneo. 23 Y le daban vino mirrado, pero él no lo tomó. 24 Y le audifican

y se reparten sus vestidos, echando a suertes sobre ellos (para ver) lo que cada uno se llevaría.

25 Era la hora tercia cuando le crucificaron. ${ }^{26}$ Y estaba la inscripción de su causa escrita encima: «EL REY DE LOS JUDÍOS». 27 Y con él crucifican a dos salteadores, uno a la derecha y otro a su izquierda. [28 Y se cumplió la Escritura que dice: con los malvados fue contado.]

29 Y los que pasaban le injuriaban, meneando la cabeza y diciendo: "¡Ah!, el que destruye el Santuario y lo edifica en tres días, 30 ¡Sálvate a ti mismo bajando de la cruz!».

31 Igualmente también burlándose los sumos sacerdotes entre ellos con los escribas, decían: "A otros salvó, a si mismo no puede salvarse; 32 que baje ahora de la cruz, para que veamos y creamos, „EL CRISTO, EL REY DE ISRAEL!».

También le insultaban los que con él estaban crucificados.

33 Llegada la hora sexta, se hizo oscuridad sobre toda la tierra hasta la hora nona. ${ }^{34} \mathrm{Y}$ a la hora nona con fuerte voz JESÚS gritó: «ELO', ELOÍ, ¿LEMA SABACTANÍl?», -que significa- "¡DIOS MIOO, DIOS MIOI ¿POR QUÉ ME HAS ABANDONADO?».

35 Y algunos de los presentes al oírlo decían: "Mira, llama a Elías». 36 Alguien, corriendo, y empapando una esponja en vinagre, sujetándola a una caña, le ofrecía de beber, diciendo: "Dejad, veamos si viene Elías a descolgarle».

37 Pero JESÚS emitiendo una gran voz, expiró. ${ }^{38}$ Y el velo del SANTUARIO fue rasgado en dos, de arriba hasta abajo.

39 Viendo el centurión, que estaba presente frente a él, que así había expirado, dijo: «VERDADERAMENTE ESTE HOMBRE ERA HIJO DE DIOS».

40 Había también unas mujeres mirando desde lejos, entre las cuales, también María Magdalena, María la madre de Santiago el menor y de Joset, y Salomé, 41 las cuales le seguían y le servían cuando estaba en Galilea, y otras muchas que subieron con él a Jerusalén.

42 Y ya la tarde llegada, como era la Preparación, es decir, el antesábado, 43 viniendo José de Arimatea, miembro respetable del Consejo, que también él estaba esperando el REINO DE DIÓS, teniendo valor entró donde Pilato y pidió el cuerpo de JESÚS.

44 Pilato se maravilló de que ya estuviese muerto, y haciendo llamar al centurión, le preguntó si hacía tiempo (que) murió. 45 Informado por el centurión, concedió el cadáver a José, 46 y comprando una sábana, descolgándole (lo) envolvió en la sábana y lo puso en un sepulcro que estaba excavado en roca; e hizo rodar una piedra sobre la puerta del sepulcro.

47 María la Magdalena y María la de Joset. observaban dónde era puesto. 


\subsection{COMPOSICIÓN}

Esta secuencia se compone de 5 pasajes. En el extremo superior el primero y segundo pasaje hablan acerca de la crucifixión (siete veces en los vv. 21. 25.24.27.30.32ac) que sufrió Jesús y en el extremo inferior, el cuarto y el quinto pasaje tratan acerca de la muerte (cuatro veces en los vv. 37.39.44.45) y sepultura ( 2 veces en el v. $46 \mathrm{bc}$ ) de Jesús respectivamente, al centro un pasaje da cuenta de la oración de Jesús. En el primer pasaje y el quinto pasaje se mencionan dos nombres propios con su correspondiente lugar de proveniencia: "Simón de Cirene" que ayudó a Jesús a llevar su cruz (v. 21) y "José de Arimatea" que dio sepultura a Jesús (v. 43).

Se relacionan porque cada uno de los pasajes contiene un título referido a la divinidad: a) "El Rey de los judíos" (v. 27), b) " $E l$ Cristo, el Rey de Israel!'(v. 32) c) "Eloí, Eloí, ¿lema sebactani? - que significa - ¡Dios mío, Dios mío ¿por qué me has abandonado?!" (v. 34), d) "Verdaderamente este hombre era Hijo de Dios" (v. 39), e) "Reino de Dios" (v, 43). Otro elemento que aparece repetidamente son los verbos que denotan traslado, movimiento: que pasaba, llevara (v. 21), conducen (v. 22) que pasaban (v. 29), bajando (30), que baje (v. 32) llegada (v. 33), corriendo (v. 36), seguían, subieron (41ab), llegada (42), viniendo (43). Igualmente el verbo decir, vuelve en: que dice (v. 28), diciendo (v.29.36), decían (v. 31.35), dijo (v. 39), al que se suma desde un punto de vista semántico el verbo gritar (v. 34). También los verbos de la visión concurren en: veamos (v. 32.36), se hizo oscuridad (v. 33), viendo (v. 39), mirando (v. 40), observaban (v. 47). Asimismo comparecen dos salteadores como acompañantes de Jesús en la cruz, que no tienen nombre propio (v. 27) y dos son las mujeres testigos de la sepultura de Jesús, que sí tienen nombre propio (v. 47) en el primer y quinto pasaje; de igual manera se presenta el plural los que con él estaban crucificados (v. 32c) y unas mujeres mirando desde lejos (v. 40) en la parte final de los pasajes segundo y cuarto. De igual forma, hay una frase que se explica en cada una de las tres secuencias: lugar del Gólgota (v. 22: que significa), Eloí, Eloí, ¿lema sabactaní? (v. 34: que significa) y la Preparación (v. 42: es decir). Por último, la cronología de los hechos narrados en el primer pasaje se rememora la hora tercia (v. 25), en el pasajè central se indica la hora sexta y la hora nona (vv. 33.34), y en el último pasaje se alude a la tarde llega$d a($ v. 42).

Se diferencian debido a que cada uno de los pasajes va exponiendo sucesivamente: a) la crucifixión (vv. 21-28), b) los insultos proferidos en contra de Jesús (vv. 29-32), c) la oración de Jesús (vv. 33-36), d) el deceso de Jesús (vv. 37-41) y e) la sepultura (vv. 42-47). Otra diferencia es que en los dos primeros pasajes no se menciona para nada el nombre de Jesús, se usa en su lugar el 
pronombre, en cambio en el tercero, cuarto y quinto pasaje comparece el nombre de Jesús (v. 34.37.43).

\subsection{INTERPRETACIÓN}

Un justo crucificado y contado entre los malhechores, rechazado por sus compatriotas, tomado como blasfemo que se pone a la altura de Dios, ridiculizado como rey fracasado por los poderosos de turno, a Jesús le condenan con el castigo que solamente se infligía a los esclavos de su tiempo. Ninguno de los que le condenaron creyó en su mensaje, por eso se burlan de él con toda clase de gestos y palabras infamantes. Pero, detrás de los títulos burlescos y de la desaprobación total de su persona, irónicamente este Jesús es verdaderamente Rey. Es Dios que se sirve de la debilidad, del mismo pecado humano, de lo irrisorio para revelarse como el Salvador. Jesús, ha sido separado de la sociedad supuestamente pura, considerado como escoria de la misma, por eso le sacan fuera de los muros de la ciudad $(15,20)$, literalmente derrotado a los ojos de sus adversarios, logran que se le cuente entre los malhechores, sin embargo lo que no logran es detener los planes de Dios.

La cruz se convierte en trono, los insultos de los no blasfemos convierte a los que las profieren en verdaderas blasfemias contra aquel que en ningún momento ha querido ni ha blasfemado con sus palabras y actitudes: "¿como contra un salteador habéis salido a prenderme con espadas y palos? Todos los dias estaba junto a vosotros enseñando en el Templo, y no me detuvisteis" (Mc 14,48-49a).

La derrota de sus oponentes viene ciertamente de parte Dios, que se sirve de la boca de los supuestamente cómplices de la muerte de Jesús, del centurión que confiesa que Jesús es el Hijo de Dios, y de José de Arimatea, el miembro del Sanedrín que sepulta a Jesús con honores de Rey, porque estaba esperando el Reino de Dios.

La oración de Jesús. Ocupa el centro de la secuencia. Lo cual quiere decir que esta oración tiene una importancia singular. Retado a que realice señales milagrosas, bajando de la cruz y salvándose a sí mismo, no obtienen ninguna respuesta, sino la confiada oración del crucificado dirigida a su Padre Dios, pues, toda la oración que encierra el Sal 22 , no es una oración de exasperación, sino es la de aquel que espera ser escuchado por Dios que no abandona a nadie que le invoca convencido de su inócencia. No es la oración de aquel que espera el triunfo personal, tampoco la venganza, sino que espera la justicia que viene de Dios. 
Los que escuchan su oración, no se sabe si no comprenden o no quieren comprender, ensañados en la ceguera de su odio hacia al que está colgado en la cruz, en vez de empezar a temer por su propia suerte, se burlan una vez más de quien han mandado crucificar con mentiras.

Dios no tarda en responder. Después de las tinieblas que son el signo del juicio de Dios, el velo del Templo fue rasgado y el grito extraordinario provocó la conversión de uno de los hombres que sabían leer los signos que el Señor pone a los hombres para moverles al cambio. Por paradójico que esto parezca ese hombre es un pagano, alguien despreciable para los judíos. Nuevamente, los supuestamente justos no se sienten impulsados a la conversión. Los que creen tenerlo todo, no necesitan de Dios, no están dispuestos al cambio de conducta.

Sepultado como Rey de la humanidad, con el reposo de Jesús en el sepulcro, se inicia el reinado del nuevo Rey que surge de las entrañas de la nación judía, para reinar entre los judíos que creyendo en su mensaje se convierten, con José de Arimatea como uno de los primeros; entre los paganos que reconocían su presencia, como el endemoniado de Gerasa, un pagano, que proclama a Jesús: Hijo de Dios Altísimo (Mc 5,6), así el centurión. Entre los discípulos que Jesús ha ido eligiendo a lo largo de su predicación, hay unas que permanecen fieles hasta el último momento, son las mujeres que observan todo en silencio. Se completa así el cuadro de los que desde ahora reconocen en Jesús al Mesías que debía venir, el Hijo del hombre que moriría y resucitaría al tercer día. La nueva comunidad está constituida más que por una raza, por hombres y mujeres que se unen a través de una misma fe, de una misma esperanza. Esta comunidad tiene la tarea de anunciar al mundo la Buena Noticia de este nuevo Rey.

\section{CONCLUSIÓN}

El haber estudiado paso a paso, cada uno de las subsecuencias de Mc 15,21-47, permite decir que en este texto existe una organización de tipo retórico bien lograda, en el sentido de que cada uno de los elementos forman un todo coherente. Es decir, en los cinco pasajes se mueven unos personajes que re-gresan una y otra vez hasta que el lector pueda darse cuenta quiénes han sido los directos responsables de la muerte de Jesús. Éstos sin duda han sido los romanos y los judíos. E igualmente, puede darse cuenta qué alcances tiene esta muerte desde un punto de vista del plan divino y de la manera como la presenta Marcos. 
En el primer pasaje, los actores principales son los soldados romanos, que en son de desprecio y de punición crucifican a Jesús con el cargo de: "El Rey de los judíos". Detrás de este cargo está la consideración de un rey fracasado, despreciado. Le desnudan para causarle la vergüenza más ignominiosa que se pueda infligir a un hombre. Le cuentan entre los malhechores, como un peligro a nivel político. Solamente Simón de Cirene, requisado, ayuda a Jesús a llevar el "patibulum" hasta el lugar llamado Gólgota, donde será realizada la crucifixión.

En el segundo pasaje, los protagonistas son los judíos, que también desacreditan a la persona de Jesús con toda clase de insultos, hasta pedirle que se salve a sí mismo bajando de la cruz y atribuirle de ser falsamente: "El Cristo, el Rey de Israel". No le creen, le tienen por un Mesías iluso, por un falso Rey, uno que ha pretendido erigirse como tal. Entre ellos se cuenta a los transeúntes, a los sumos sacerdotes y a los escribas, y a los mismos compañeros de suplicio.

En el pasaje central se juntan judíos y romanos, que interpretan mal la oración de Jesús: Dios mío, Dios mío ¿por qué me has abandonado?, mofándose de que en vez de orar estuviese llamando al profeta Elías, que según la creencia popular salva a los justos en circunstancias cercanas a la muerte. Pero, la confusión de los presentes y la del soldado romano, es una acusación para ellos mismos, de su endurecimiento, de su ceguedad al no querer comprender que el crucificado no es lo que ellos piensan. Es realmente un justo.

Cuando los presentes están esperando vanamente la venida de Elías en el cuarto pasaje, Jesús muere. Entonces sucede una serie de signos. Es rasgado el velo del Santuario, Dios interviene. El jefe de su ejecución, el centurión, un pagano, confiesa: "Verdaderamente este hombre era Hijo de Dios". El curso de los hechos comienza a cambiar, a quien acaban de ver morir, alguien empieza a tenerle por justo. Mientras las mujeres, desconocidas hasta entonces, resultan ser discípulas que seguían y servían a Jesús cuando estaba en Galilea, lugar donde comenzó la historia de Jesús. Éstas subieron con él a Jerusalén, lugar donde acaba de morir el Maestro. Ellas miran desde lejos en silencio, impotentes.

Aparece, en el quinto pasaje, un nuevo personaje, para cumplir con un precepto legal estrictamente judío, dar sepultura a los condenados. Se juntan nuevamente judíos y romanos, no ya como cómplices sino para honrar con la sepultura a aquel que acaba de fallecer, aunque el mérito es totalmente de José de Arimatea, un Judío importante, un miembro del Sanedrín, que se encarga de todos los detalles y preparativos, comenzando por pedir a Pilato los restos del condenado, pues estaba esperando el Reino de Dios. Esta sepultura es la del Nuevo Rey. Las mujeres una vez más, miran dónde era depositado el cadáver de aquel a quien hasta ahora séguían. 
Una historia así, no tendría la menor trascendencia, si detrás del relato no se movieran las pinceladas literarias y teológicas del escritor, la participación del lector que está envuelto en el argumento, evidenciando el cumplimiento de las Escrituras, del plan de Dios que se realiza por encima de la voluntad humana. En el fondo hay una ironía, a través de la cual se puede entender progresivamente, que Jesús es en verdad Rey de los judíos, que tiene un servidor llamado Simón de Cirene y un soldado en la persona del centurión; que Jesús, es en realidad el Cristo, Rey de Israel, el pueblo que Dios se había elegido en el Antiguo Testamento, es el ungido de Dios. Este Jesús es consciente de la voluntad del Padre, aunque se lamenta de su aparente abandono, pero a la vez, anuncia su inocencia, su falta de culpabilidad, no es un maldito de Dios, pese a que los demás lo tienen por blasfemo. Evidentemente, Jesús es el Hijo de Dios, es más que el profeta Elías, él mismo es la salvación, su sangre es derramada por muchos, su muerte tiene efectos redentores. La salvación no es solamente para los judíos, con la presencia de Simón de Cirene, las mujeres judías y José de Arimatea, es también, de ahora en adelante, para los paganos en la persona del Centurión. Para ello basta aceptarlo, creerlo, seguirlo y tener la suficiente valentía como la de José de Arimatea para ser parte de su causa, que no es de muerte sino de vida. Los que acusan a Jesús de blasfemo, son en realidad blasfemos al burlarse del ungido de Dios.

En el momento mismo de su muerte, Jesús, sigue haciendo discípulos como hizo desde el principio del evangelio de Mc. La validez de su ministerio ahora viene confirmada por Dios que hace caer las tinieblas como signo de juicio para los incrédulos, sean romanos o judíos; rasgando el velo del Santuario, Dios da acceso a su presencia no solamente a los sumos sacerdotes, judíos, sino también a los paganos, a los no elegidos de antemano.

Como en la transfiguración están presentes tres discípulos, Pedro, Santiago y Juan, ahora en el momento de su muerte están presentes tres discípulas suyas, María la Magdalena, la otra María y Salomé. Como en su crucifixión están dos malhechores sin nombre a su derecha y a su izquierda, en el momento de su sepultura están presentes dos discípulas, con nombre María la Magdalena y María la de Joset.

Como en su bautismo, vino sobre él el Espíritu Santo, ahora cuando expira, deja escapar su espíritu. Como Elías tenía que venir para ser su precursor, Juan el Bautista hace sus veces, quien ni siquiera se tiene como digno de desatarle la correa de sus sandalias, porque solamente le prepara el camino; Jesús es más que Elías, más que Juan el Bautista, es el Mesías, el que debía venir y que, según sus palabras, debía sufrir, debía morir, debía beber el trago amargo de la muerte. Muere como un justo sufriente, porque en silencio ha soportado toda clase de infamias, calumnias y blasfemias, para que se haga la volun- 
tad de su Padre. La Nueva Alianza, el Reino de Dios, se ha fundado con su sangre derramada en la cruz, como lo predijo en la Cena Pascual. Las discípulas que lo han visto todo, ahora deben anunciarlo para que la Buena Nueva de Dios llegue a todos los confines de la tierra y se conviertan, cambien de conducta.

Como en el llevar la cruz le ayuda un tal Simón de Cirene, un judío cualquiera, requerido por los soldados, los subordinados del poder reinante, el encargado de su sepultura es un tal José de Arimatea, un judío importante, de la clase del poder religioso, después de pedir el cuerpo de Jesús a un romano importante, a Pilato, el representante del poder político.

Las Escrituras se cumplen cuando los soldados se reparten sus vestidos; cuando se mofan de él; cuando le piden salvarse a sí mismo bajando de la cruz, queriendo comprobar si sus palabras son ciertas; cuando caen las tinieblas como señal de juicio; cuando el soldado le ofrece de beber vinagre; con el gesto de José de Arimatea al darle sepultura. La oración de Jesús, no es precisamente el cumplimiento de las Escrituras, pero sirve para leer esta secuencia a la luz del Salmo 22, como el sufrimiento del justo. Elementos todos, que sirven para conectar la muerte de Jesús con la historia de la Salvación, tal y como Marcos lo ha entendido: la muerte del justo sufriente, a quien Dios salva, por ser el Hijo amado, el Cristo; en quien Dios se ha complacido y a quien hay que escucharle y seguirle. 


\section{BIBLIOGRAFIA}

\section{LIBROS}

Aland, K., Synopsis Quatuor Evangeliorum, Deutsche Bibelgesellschaft Stuttgart, $1990^{13}$.

Alonso SchöKel, L. CARniti, C., Salmos I, Borla, Roma, 1992, 427-452.

BibBia Tов (Traduction Oecuménique de la Bible), Elle di ci, Torino, 1992, 2308-2310.

Biblia de Jerusalén, Desclée de Brouwer, Bilbao, 1976, 55.

Billerbeck, P. - Strack, H., Kommentar zum Neuen Testament aus Talmud un Midrasch, Vol. I, München, 1961, 344.

Blass, F. - Debrunner, A., Grammatica del Greco del Nuovo Testamento, (Título Original: Grammatik des Neutestamentlichen Griechisch, Vandenhoeck \& Ruprecht, Göttingen, 1976), Paideia, Brescia, 1982.

Blinzler, J., Il processo di Gesú, Paideia, Brescia, 1966, 327-394.

Costacurta, B., Con la cetra e con la fionda. L'ascesa di Davide verso il trono, Dehoniane, Roma, 1995², 223.

Diccionario de la Lengua Española, Tomos I-II, Espasa Calpe, Madrid, 1992.

Galizzi, M., Vangelo secondo Marco, Elle di Ci, Torino, 1993, 288-301.

GNilKa, J., Marco, Cittadella, Assisi, ${ }^{21991, ~ 872-912 . ~}$

Grande Lessico del Nuovo Testamento ( $G L N T$ ), Vol. I-XVI, a cargo de G. KITTEL - G. FRIEDRICH (Título Original : Theogishes Wörterbuch zum Neuen Testament, W. Kohlhammer, Verlag, Stuttgart, 1933-1978), Paideia, Brescia, 1965-1992.

Guerra Gómez, M., El idioma del Nuevo Testamento, Aldeacoa, Burgos, ${ }^{3} 1981$.

Guevara, H., Ambiente político del pueblo judio en el tiempo de Jesús, Cristiandad, Madrid, 1985.

Lacueva, F., Nuevo Testamento interlineal Griego-Español, Clie, Barcelona, 1984.

LANE, W. L., The Gospel according to Mark, Gran Rapids, Michigan, 1974, 560-581.

LÉGASSE, S., El proceso de Jesús. La historia, Desclée De Brouwer, Bilbao, 1995.

, El proceso de Jesús. La Pasión en los cuatro Evangelios. Desclée De Brouwer, Bilbao, 1996.

MANN, C.S., Mark, The Anchor Bible 27, Doubleday, New York, 1986, 643-658.

Mateos, J. - CAMACho, F., Marco, Cittadella, Assisi, 1996, 380-394. 
Metzger, B. M., A textual commentary on the Greck New Testament, Deutsche Bibelgesellschaft / United Bible Societies, Stuttgart, $1994^{2}$.

MEYNET, R., E ora, scrivete per voi questo cantico. Introduzione prattica all'analisi retorica, Dehoniane, Roma, 1996.

- L'analisi retórica, Querinniana, Brescia, 1992.

- Passion de notre Seigneur Jésus Christ, Du Cerf, París, 1993.

Nestle-Aland, Novum Testamentum Graece, Deustsche Bibelgesellschaft, Stuttgart, $1994^{27}$.

NolLI, G., Evangelo secondo Marco; texto greco, neovolgata latina analisi filologica, traduzione italiana, Editrice Vaticana, Città del Vaticano, ${ }^{3} 1992$, 404-420.

Pesch, R., L'evangelo della comunità primitiva, Paideia, Brescia, 1984, 698.

PIKAZA, X., Il vangelo di Marco, Borla, Roma 1996, 406-420.

Pontificia Comisión BíBlica, La interpretación de la Biblia en la Iglesia, Libreria editrice Vaticana, Vaticano, 1993, 36-39.

RADERMAKers, J., Lettura pastorale del vangelo di Marco, Dehoniane, Bologna, 1987, 313-328.

RaVASI, G., I libro dei Salmi. Commento e attualizazione I, Dehoniane, Bologna, 1981, 395-424.

SchnAckenburg, R., El Evangelio Según san Marcos, Vol. II, Herder, Barcelona, 1973, 313-333.

SEPTUAGinTA, Deutsche Bibelgesellschaft, Stuttgart, 1979.

TAYLOR, V., The Gospel According to St. Mark, St Martin's Press, London, $1959^{5}, 586-602$.

URICChIO, F.M. - Stano, G.M., Vangelo secondo Marco, Marietti, Torino, 1974², 626-646.

Zerwick, M. - Grosvenor, M., An Analysis of the Greek New Testament, Roma, 19934, 162-164.

Zerwick, M., Analysis philologica Novi Testamenti Graeci, Roma, 1953, 123125.

\section{ARTÍCULOS}

ARNDT, W. - GINGRICH, F.W., “ $\alpha \gamma \gamma \alpha \rho \varepsilon v ́ \omega ”, ~ G E L N T$, Translation of: BAUER, W., GDwsNT, Chicago, 1957.

BALZ, H. - SCHNEIDER, G., "ßoów”, DENT, Vol. I, 669-670.

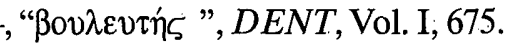

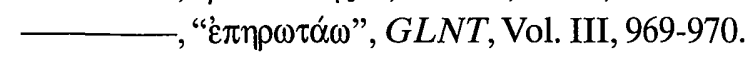

BARnouin, M., "Marie, mére de Jacques et José' (Marc 15.40). Quelques observations", NTS 42 (1996) 472-474. 


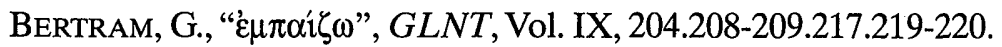

BETZ, O., “ $\phi \omega v \varepsilon \omega ”, ~ G L N T$, Vol. XV, 340.343-344.

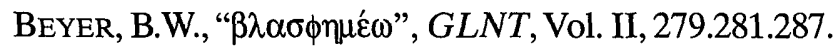

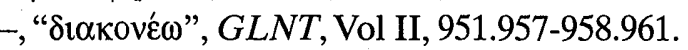

BlounT, B.K., "A Socio-Rhetorical analisys of Simon of Cyrene: Mc 15:21 and Its parallels", Sem 64, 2 (1993) 171-198.

BROWER, K, “(Mk 15,35) Elijah in the Markan passion narrative”, JSNT 18 (1983) 85-101.

Brown, R.E., "The Burial of Jesus (Mark 15: 42-47)”, CBQ 50 (1988) 233-245.

CAZA, L., "(Mc 15:34) Le relief que Marc a donné au cri de la croix", ScEspr 39 (1987) 171-191.

Clark, K.W., "Golgotha”, IDB, Abingdon Press, New York, 1962, 439.

EsCAFFRE, B., "La mort de Jésus et la venue du royaume dans l'evangile de Marc", EstBib 52 (1994) 329-339.

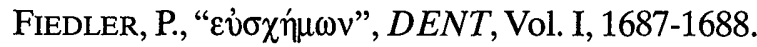

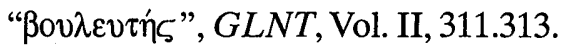

FISHER, L.R., "Betrayed by Friend. And expository of Psalm 22", Interp 18 (1964) 20-38.

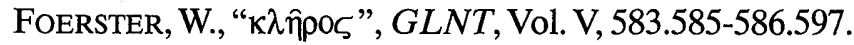

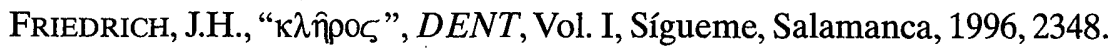

GrÁNDEZ, R.M., "Las tinieblas en la muerte de Jesús. Historia de la exégesis de Lc 23, 44-45a (Mt 27, 45; Mc 15, 33)”, EstBib 47 (1989) 177-223.

Greeven, H.W., "عنं $\xi \dot{\eta} \mu \omega v$ ”, GLNT, Vol. III, 1195.1197.1198-1199.

HAAG, H. - van den BoRn, A.,-de Ausejo, S., "Crucifixión", $D B$, Herder, Barcelona, $1987^{\circ}, 404-405$.

HAUCK, F., "ßó $\lambda \lambda \lambda \omega ", ~ G L N T$, Vol. II, 35-36.

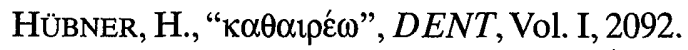

LEON-Dufour, X., "Vergogna e nudità", $D T B$, Marietti, Casale Monferrato, $1984,1355$.

—, "Veste", DTB, Marietti, Casale Monferrato, 1984, 1366.

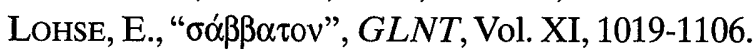

MATERA, F.J., "The prologue as the interpretative key to Mark's Gospel", JSNT 34 (1988) 3-20.

MEYNET, R., "Un nuevo metodo per comprendere la Bibbia: l'analisi retorica", Greg 77, 3 (1996) 403-436.

Michaelis, W. " $\sigma \mu \nu \rho v i \zeta \omega ”, ~ G L N T$, Vol. XII, 673-674.678-680.

MILLER, D.L., "EMПAIZEIN: Playing the Mock game (Luke 22: 63-64)", JBL, 90 (1971) 309-313.

O'Collins, G.-KENDALl, D., "Did Joseph of Arimatea Exist?”, Bib 75 (1994) 235-241. 
Pesch, R., "Il Vangelo di Marco, Parte Seconda, Texto Greco e Traduzione, Commento ai Capp. 8, 27-16,20", CTNT, Paideia, Brescia, 1982, 694-723. PILCH, J.J., "Death with Honor: The Mediterranean Style Death of Jesus in Mark", BTB 25, 2 (1995) 65-70.

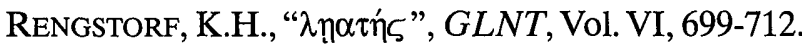

REumanN, J.H., "Psalm 22 at the Cross. Lament and Thanksgiving for Jesus Christ", Interp 28 (1984) 39-58.

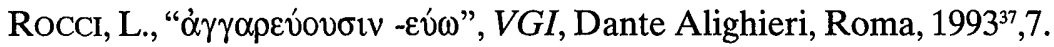

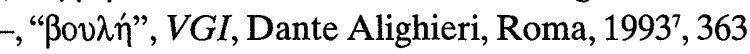

SCHEIFLER, J.R., "El Salmo 22 y la crucifixión del Señor", EstBib 24 (1965) 5-83.

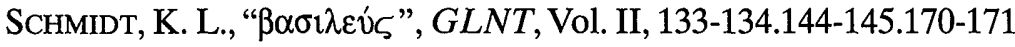

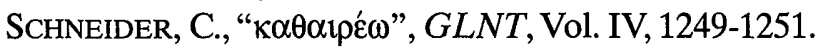

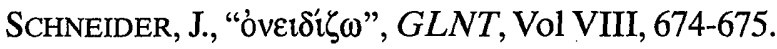

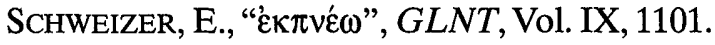

STAUFFER, E., “ßoó $\omega ”, ~ G L N T$, Vol. II, 292.296-297.

UNTERBMAIR, F.G., "غ $2 \mu \pi \alpha i \zeta \omega$ ", DENT, Vol. I, 1359-1361.

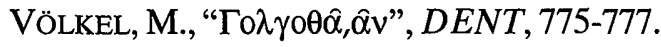

